Portland State University

PDXScholar

1979

\title{
Functional analysis of Great Basin projectile points
}

Roger Wiggin

Portland State University

Follow this and additional works at: https://pdxscholar.library.pdx.edu/open_access_etds

Part of the Archaeological Anthropology Commons Let us know how access to this document benefits you.

\section{Recommended Citation}

Wiggin, Roger, "Functional analysis of Great Basin projectile points" (1979). Dissertations and Theses. Paper 2794.

https://doi.org/10.15760/etd.2789

This Thesis is brought to you for free and open access. It has been accepted for inclusion in Dissertations and Theses by an authorized administrator of PDXScholar. Please contact us if we can make this document more accessible: pdxscholar@pdx.edu. 
AN ABSTRACT OF THE THESIS OF Roger Wiggin for the Master of Arts in Anthropology presented November 19, 1979.

Title: Functional Analysis of Great Basin Projectile Points. APPROVED BY MEMBERS/OF THE THESIS COMMITTEE:

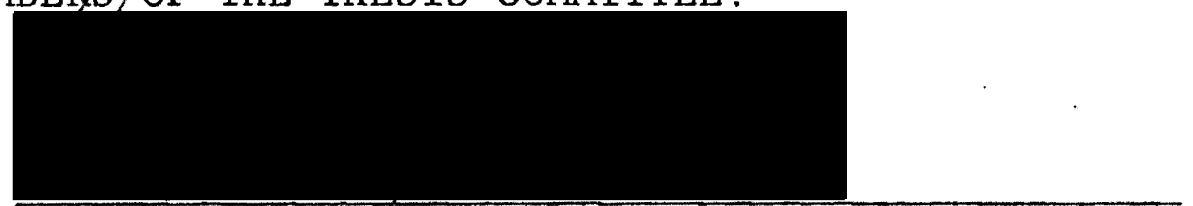

Marc R. Feldesman, Chairman

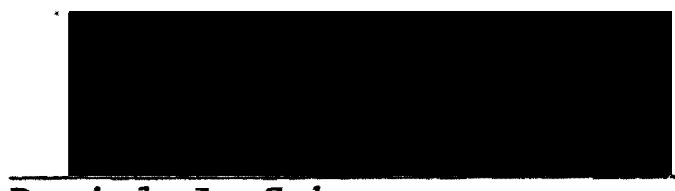

Daniel J. Scheans

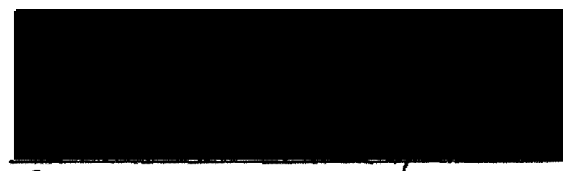

Thomas McLean

This paper presents a refined methodology for distinguishing the stone points of arrows from the stone points of spear thrower darts in archeological assemblages from the Great Basin. The methodology was developed from a sample of 111 complete stone points collected during the archeological reconaissance and testing of the Malheur National Wildlife Refuge, Harney County, Oregon, 1971-1974. The points were measured for five metric variables and frequency histograms of each variable were generated by computer. The effectiveness of each variable as an index of func- 
tional class (i.e., arrow point vs. dart point) was judged on the basis of the apparent bimodality of its curve and the $t-$ test. The variables of weight and neck width showed significant bimodality, confirming the work of previous researchers. A new variable, stem thickness, also showed significant bimodality. All three can be considered useful indices of functional class. They also appear to be functionally independent. An attempt was made at developing a multivariable index of point function, using a mutivariable clustering analysis, the $\mathrm{K}$-means test. Results of the K-means test were inconclusive but showed promise for further development. 
FUNCTIONAL ANALYSIS OF GREAT BASIN

PROJECTILE POINTS

by

ROGER WIGGIN

A thesis submitted in partial fulfillment of the requfrements for the degree of

\author{
MASTER OF ARTS \\ in \\ ANTHROPOLOGY
}

Portland State University

1979 
TO THE OFFICE OF GRADUATE STUDIES AND RESEARCH:

The members of the Committee approve the thesis of Roger Wiggin presented/November 19, 1979.

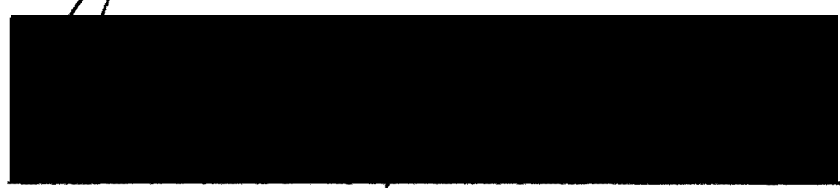

Marc R. Feldesman, Chairman

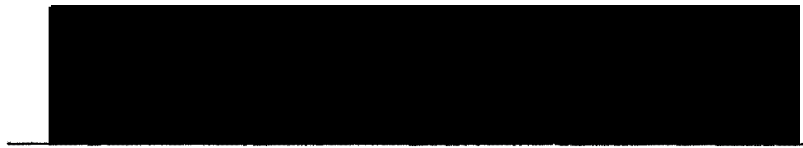

Daniel J. Scheans

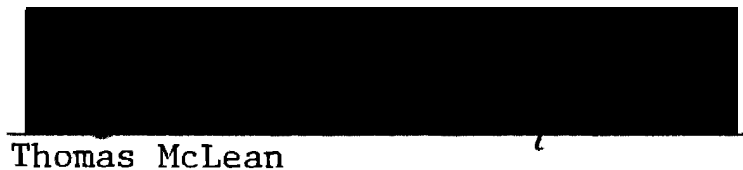

APPROVED :

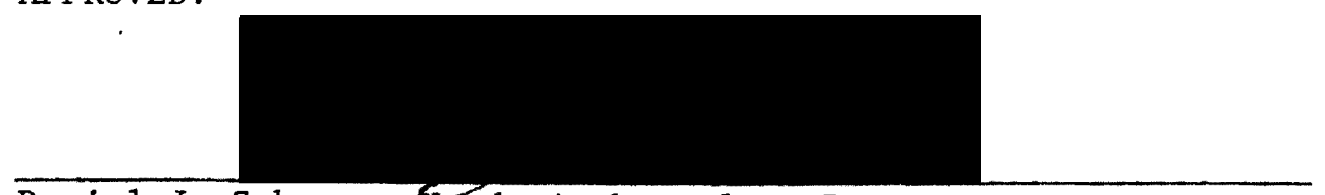

Daniel J. Scheans, Head, Anthropology Department

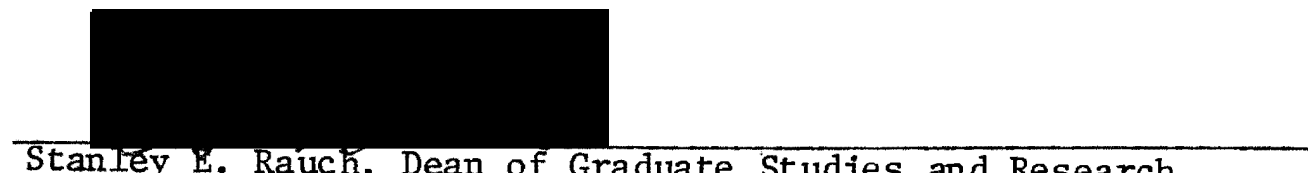




\section{ACKNOWLEDGEMENTS}

At this point I would like to express my deep appreciation and thanks to many people - to the members of my Committee, with special thanks to my Chalrman Marc Feldesman, whose sage advice and consummate computer skills so often bailed me out on this project; to Dean Clarkson for his concise explanation of the K-means test; to Tom Newman, mentor of the Malheur project and the early inspiration for this work; to Dan Scheans for his penetrating comments and overall help; to Melissa Berman for her generous efforts on the manuscript; to Tricia Williams for the typing; to Pangene for his lastminute darkroom work; and to all my friends and colleagues who have helped so much and listened to so much complaining about this thing over the years. 
TABLE OF CONTENTS

PAGE

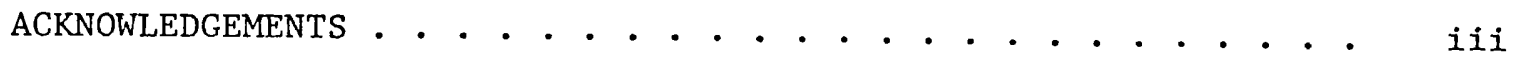

LIST OF TABLES • • • • • • • • • • • • • • • • • • • • • • • • • $\quad \mathrm{v}$

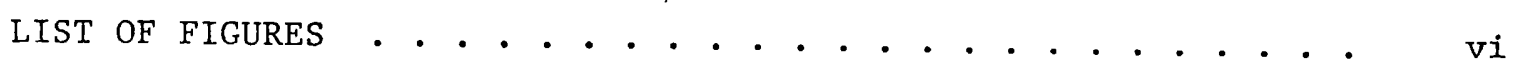

INTRODUCTION • • • • • • • • • • • • • • • • • • • • • • • • 1

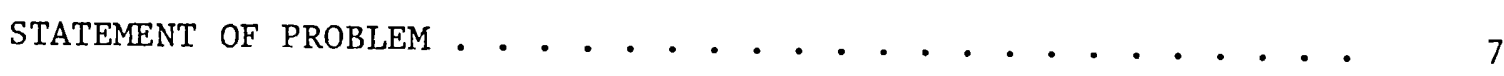

SAMPLING • • • • • • • • • • • • • • • • • • • • • • • • • • • • 15

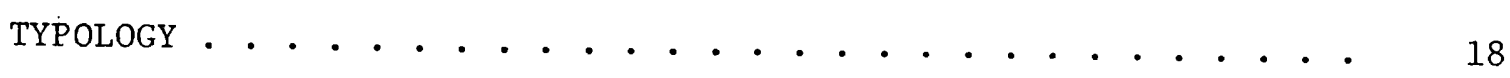

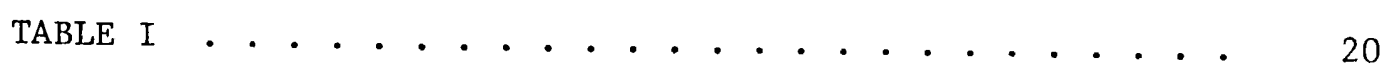

FIGURE 1 • • • • • • • • • • • • • • • • • • • • • • 22

FIGURE 2 • • • • • • • • • • • • • • • • • • • • . . . 23

KEY TO FIGURES 1 and 2 . . . . . . . . . . . . . . . . . . . . 24

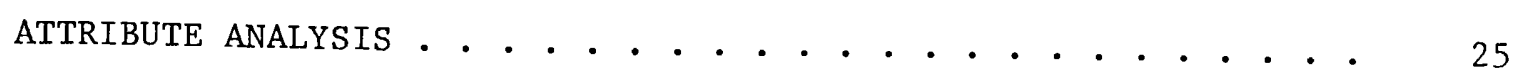

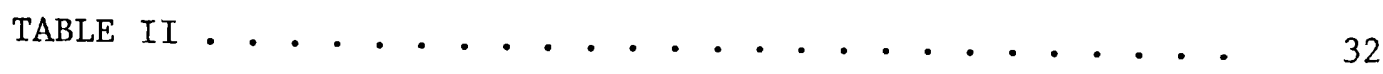

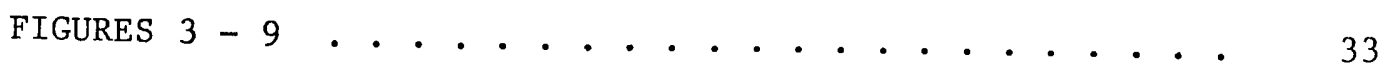

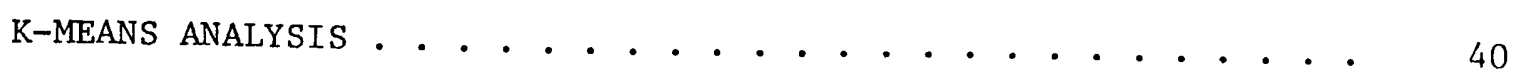

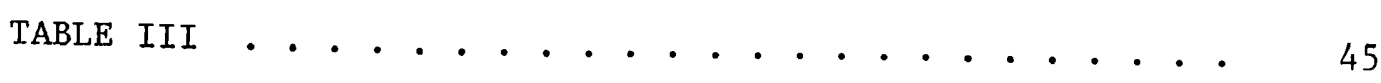

CONCLUSIONS

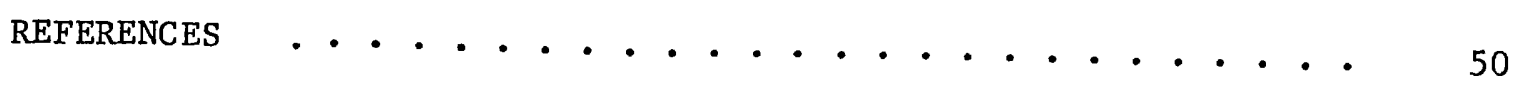




\section{LIST OF TABLES}

TABLE

PAGE

I Malheur Point Typology and Metric Data Summary • • • • . 20

II T-Test Results . . . . . . . . . . . . . . . . 32

III K-Means Results . . . . . . . . . . . . . . . 45 


\section{LIST OF FIGURES}

FIGURE

PAGE

1. Representative Specimens of Malheur Points, Series 1 . . . 22

2. Representative Specimens of Malheur Points, Series 2-4

Residual .................... . 23

Key to Figures 1 and 2 . . . . . . . . . . . . . 24

3. Histogram of Weight . . . . . . . . . . . . . . . 33

4. Histogram of Length . . . . . . . . . . . . . . . 34

5. Histogram of Maximum Width . . . . . . . . . . . . 35

6. Histogram of Neck Width . . . . . . . . . . . . . 36

7. Histogram of Stem Thickness. . . . . . . . . . . . . 37

8. Histogram of Shape (Length/Width Ratio). . . . . . . . . . 38

9. Histogram of Frontal Area (Maximum Width x Stem Thickness) . 39 


\section{INTRODUCTION}

The purpose of this paper is to present a refinement of the methodology introduced by Fenenga (1953) and developed by Forbis (1960), Binford and Papworth (1962), Wyckoff (1964), and Corliss (1972) for the identification of archeological projectile points as their probable use, either as dart points or arrow points. Darts are defined as projectiles thrown by the spear thrower or atlat1. Arrows are defined as projectiles propelled by the bow. Projectile points are defined as small, bifacially chipped stone artifacts of a shape which would admit to their use as points of darts or arrows. The sample of projectile points from which this refinement was developed comes from the Malheur National Wildlife Refuge, Harney County, Oregon, in the northern Great Basin, and the discussions which follow will focus on the Great Basin for the most part; however, I hope that this refined methodology will be applicable to any sample of notched projectile points.

The spear thrower was used in the old World in very ancient time. The earliest known archeological specimens are found in Magdalenian assemblages from Western Europe, dated c.a. 15,000 B.P. (Massey 1961). The spear thrower may have been brought to the New World by the earliest immigrants to this hemisphere during the last glacial period. In the New World, spear thrower hooks have been found in strata dated to c.a. 8,500 B.P. at Fort Rock Cave, in the northern Great Basin, and at Five Mile Rapids on the Columbia River (Cressman 1977:105). The oldest complete spear thrower from the New World was found at Winnemucca Lake, Nevada, 
and dates to about 8,000 B.P. (Mildener 1974:10).

The spear thrower, or atlatl as it is usually called in the New World, probably had continent-wide distribution in North America before the introduction of the bow (Baker and Kidder 1937:51). It was used by some aboriginal groups in the Arctic and Central Mexico as late as ethnohistoric times; it is still used by the natives of the Western Desert of Australia (Gould 1969). Krause (1902) has classified spear throwers as being of three basic types: male, female, and mixed. Male spear throwers have a projecting spur or hook at the distal end which engages the butt of the dart. Female spear throwers have a dorsal groove combined with a distal abutment or cup for engaging the butt end of the projectile. Mixed types have both a hook and a groove. All three types are known from the Great Basin, the male and mixed types predominating. (Mildener 1974:20). Cressman (1977:105) has subdivided the male and mixed types into simple and compound types, simple forms showing an integral carved hook and compound forms showing separate, lashed-on hooks. The present archeological data suggest that the compound atlatl antedates the simple type in the Great Basin: however, the sample size of these artifacts is small and this temporal relationship is by no means firmly established. (Mildener 1974:21).

Great Basin darts are of two main types, those with solid wood mainshafts and those with mainshafts of phragmites (reed). The former type is known from Hogup Cave (Dalley, in Aikens et al 1970:154-155), and the latter is known from various sites, notably Leonard Rockshelter (Heizer 1951). Both types use separate wooden foreshafts articulating with distal sockets in the main shaft; the reed-shafted types may also 
have a separate proximal or butt shaft of reed or wood to which fletching was sometimes attached. Darts used with male or mixed type atlatls show a distinctive conical socket at the proximal end for engagement with the hook of the throwing board. Dart foreshafts from the Great Basin may be slotted for the hafting of a stone point, or simply sharpened into an integral point. The former types predominate; the integrally carved point may represent an emergency expedient. Blunt-ended or 'bunt'-type wooden foreshafts are also known. Complete darts are extremely rare in archeological assemblages, so metric data for the lengths of Great Basin darts is lacking. The Leonard Rockshelter dart is about 1.2 meters long (Heizer 1951:96). Wood-shafted darts may have been longer and heavier. Desert-survival and primitive technology expert Larry Dean 01sen recommends a burned willow sapling five to six feet in length (01sen 1967:132) for making a dart mainshaft. The wooden mainshaft fragments from Hogup Cave range from .9 to $1.2 \mathrm{~cm}$. in diameter.

Great Basin bows are generally simple in form, with or without rawhide or sinew backing (Wheat 1968). Bow fragments have been found in archeological sites, but no complete archeological bows are known from the area. Bows doubtlessly varied considerably in length and weight of pull with the tastes and preferences of the individual maker; Ishi, the Yani Indian who lived at the University of California Lowie Museum from 1911-1916, used a "body formula" for fudging the proper length of a bow for its user, which worked out to 44 inches for himself. Ishi made many bows and arrows and participated in the experiments of Saxton Pope; his bows ranged from 40 to 50 inches in length and averaged from 30 to 40 pounds in pul1 (Pope 1921:106). Although Ishi was not technically a Great 
Basin Indian, his bows and arrows closely resemble Great Basin archeologIcal specimens and it is probably safe to assume that Great Basin bows were of similar dimensions and power.

Great Basin arrows, like darts, were of two main types distinguished on the basis of main shaft raw material, with both solid wooden and reed mainshafts used. Reed-shafted specimens used hardwood foreshafts, with or without stone points, and are the more common type archeologically. Solid wood shafted arrows generally lack a separate foreshaft. At Hogup Cave, wood-shafted arrows appear (apparently) before reed-shafted specimens (Dalley, in Aikens, et al 1970:165) but this may be the result of disturbed stratigraphy and/or fortuitous preservation. This writer observed two woodshafted arrows recovered from a dry cave by an amateur collector in the Alvord Desert area of southeastern Oregon in 1974. They were of some light wood, probably willow, incised with a sine-wave motif and showing remnants of sinew cordage below the hafting notch of the complete specimen and bits of fletching on the butt end of the broken specimen. It was not possible to make accurate measurements of these pieces, but the complete specimen was about $90 \mathrm{~cm}$. inches 1ong. Both were about $.7 \mathrm{~cm}$. In diameter.

At the present time the origins and diffusion chronology of the bow in the Great Basin are not firmly established and it is to this end that the present research is directed. Cressman (1977:106) has reviewed the pertinent archeological data, especially the chronological distribution of atlat1--and bow--related artifacts from Lovelock Cave (Nevada) and the Oregon cave sites and concluded that the replacement of the atlat 1 occurred about 2,300 B.P. in the Western part of the Great Basin. He also notes that, at Lovelock and the Catlow Valley caves, there is apparently a con- 
siderable overlap of the two forms chronologically, indicating a slow replacement of the atlat1. Aikens (1970:199-200) suggests an earlier date for the appearance of the bow in Utah, c.a. 3,300 B.P., and the Hogup Cave sequence also shows some overlap of the two forms. Heizer, relying mainly on the California data, posits replacement of the bow C.a. A.D. 500-1000 (Hester 1973:126). If indeed the new weapon was slow to gain acceptance among the ancient Great Basin peoples, it would not be surprising to find a wide disparity in dates as the new form diffused slowly over the vast, thinly populated area. Still, the sequence of events leading to the bow's universal adoption by ethnographic times in the Basin is by no means established.

The major problem in establishing the diffusion chronology of the bow in the Great Basin is the relative paucity of truly diagnostic artifacts in a datable stratigraphic context. Atlatls, darts, bows, and arrows are all perishable artifacts and rare finds even the arid Great Basin. Complete darts and arrows are extremely rare. Mildener (1974) lists only sixteen scientifically described atlatls for the entire area. Bow fragments are not common, and I have found no reference to a complete or nearly complete bow in an archeological context for the area. Projectile fragments are more common, but less diagnostic. Foreshafts are similar for both darts and arrows except for size. Butt sections are the most diagnostic parts of projectile fragments, as the arrow butt section has the distinctive v-shaped nock for the bowstring while the dart but: section shows a conical indentation or cup for engaging the hook of the atlatl. Despite the excellent preservation found in the dry cave sites, it is unlikely that a sufficient sample of diagnostic artifacts will ever be 
found to allow a diffusion chronology to be established on the basis of perishable remains alone.

The chipped stone points used to tip darts and arrows are, however, common and almost imperishable. This paper seeks to develop a methodology by which the type of projectile (dart or arrow) may be inferred from the stone point alone for Great Basin assemblages. If successfully developed, it would greatly increase the sample size of diagnostic artifacts relevant to the origin and diffusion of the bow in the Great Basin. 


\section{STATEMENT OF PROBLEM}

There is reason to believe that the bow came into use in relatively recent times, and that prior to its introduction, or much less probable local invention, the spear thrower enjoyed continent-wide distribution in both Americas. These suppositions are based on the apparent total absence from all respectable ancient deposits of small, light points suitable for tipping arrows; and conversely, by the presence in such deposits of larger points or sizes and weights appropriate for service with the heavier, longer darts propelled by the spear thrower.

$$
\text { Baker and Kidder (1937:51) }
$$

The final solution to the problem of the origin and diffusion chronology of the bow in the Great Basin depends upon the development of a methodology by which the remains of darts may be reliably distinguished from the remains of arrows in archeological assemblages. In the Great Basin (as elsewhere) the most common remains of these projectiles are the chipped stone points used to tip them; and a methodology which can be applied to them, such that the character of the original projectile may be inferred from the point alone, is the goal of the present research. In the above quotation, Baker and Kidder have laid the foundation for such a methodology. Two fundamental assumptions are implicit in their statement. First, it is assumed that darts are larger and heavier than arrows. Second, they assume that dart points are larger and heavier than arrow points. Subsequent researchers in this field have made use of these basic assumptions, mostly because the archeological data themselves strongly suggest that a reduction in point size occurs with the introduction of the bow. This is apparent in Great Basin sites such as Lovelock Cave and the Catlow Valley Caves (Corliss 1972:Table I, V). Danger and Hogup Caves 
(Aikens 1970:44-54) where the points in more recent strata are smaller than those in more ancient strata. At Lovelock and Hogup, bow-related perishable fragments appear and atlat1-related perishable fragments disappear at the same time the small points replace the large points (Cressman 1977:106). Whether this point size reduction represents a response to purely functional limitations of the two propelling systems is not extablished. Experimental work has not resolved the question of the functional limitations of the maximum size of arrow points vs. the maximum size of dart points. There seems to be no minimum size of either dart or arrow points, as both types of projectiles are known to occur without stone points. Still, the reduction in size with the introduction of the bow has not been adequately explained. Past archeological researches have been directed toward defining an index measurement of some feature of size which can be used to segregate an assemblage into (probable) dart and (probable) arrow points.

The first researcher to apply the assumptions of Baker and Kidder to the analysis of a sample of projectile points was Franklin Fenenga (1953). He utilized a large sample of 884 points from 23 sites in the western U.S. Each point was weighed and measured for length, width, and thickness and the results plotted on frequency histograms. He discovered that weight showed a markedly bimodal distribution. Most of the sample weighed less than 3.5 grams, a significant group weighed more than 4.5 grams, and very few specimens fell between 3.5 and 4.5 grams. None of the other attributes showed a bimodal distribution. He also constructed plots of weight vs. each of the other attributes and found that there seemed to be a functional relationship between them, i.e. as a linear dimension increased, so did weight. He concluded that the linear dimensions were subsumed by weight, 
and was the most reliable index of point size.

He then considered his sample in terms of the dating of the strata from which the points came. He discovered that points from more recent strata fell into the Small Point Tradition (i.e. less than 3.5 grams) and that points from more ancient strata generally fell into the Large Point Tradition (i.e. more than 4.5 grams). He concluded that the Sma1l Point Tradition probably corresponded to arrow points and the Large Point Tradition probably corresponded to dart points. When considering weight and dating from a single site, however, he noted anomalous points, falling between the two traditions in size, which he suggested were early or "incipient" arrow points.

Fenenga discussed the findings of Cressman and Krieger (1940) in his argument. Cressman and Krieger described points from Great Basin sites as "1arge" (greater than 2 grams) and "small" (less than 2 grams). Though these points showed an apparently bimodal distribution of weight, the values are much smaller than those discovered by Fenenga, and the mean value of the "large" goup falls squarely on Fenenga's cut-off range of $3.5-4.5$ grams. Fenenga was not able to explain this apparent discrepancy.

Forbis (1960), working with points from a site in Alberta, tried another index of probable function. This is neck width, or the width of the stem at the point of greatest constriction in notched projectile points. He reasoned that this measurement represented the maximum diameter of the foreshaft. He discovered that this dimension showed a bimodal distribution and that the lobes of the bimodal curve corresponded to early (large neck width) and later (small neck width) periods at the site. He concluded that this measurement was a suitable index of function for samples which include notched forms. Binford and Papworth (1962) and Wyckoff (1964) used this 
same index on other single site collectlons, with apparent strong correlation between time and neck width dimensions.

Corliss (1972) used the neck width index with a group of sites from geographically and culturally distinct areas, using samples from sites in the Plateau and the Great Basin. He discovered that neck width showed bimodality for all sites and areas tested, but the numerical values of the means of the arrow and dart groups varied with area, i.e. both arrow and dart groups for the Plateau showed smaller mean values than the respective groups for the Great Basin. He also noted a slight difference in mean values, between the mean values of the Roaring Springs points and the Hogup points, with the latter showing the higher values, indicating a difference between the northern and eastern Great Basin areas. He concluded that the reduction in point size apparent with the change from the atlat 1 to the bow was not a response to a functional limitation but rather represented a cultural choice determined by local conditions of game, raw materials, hunting techniques, etc.

Still, point size reduction after the introduction of the bow seems to be an archeological fact, even if no purely functional explanation for the reduction has been formulated. The atlat 1 and the bow have nothing in common mechanically; they represent two different mechanical principles (Cressman 1977:108). The universal reduction in point size must represent something; the present research is directed toward its discovery, as this knowledge is essential to the reliability of any system for distinguishing the type of projectile from the point alone. A brief consideration of the functional variables which affect projectile performance with regard to their points follows.

Hunting projectiles are mechanisms by which the muscular energy of 
the hunter is transferred to the body of the game and delivered in the form of shock and tissue damage. A projectile must travel in a predictable path to the required range and deliver killing force at the target in order to be effective as a hunting tool. Thus a dart or arrow can be said to have qualities of flight ballistics and impact ballistics. Flight ballistics are determined by the initial or impulse velocity, weight, and aerodynamic qualities of the projectile. Impact ballistics are determined by the remaining velocity at impact, the weight of the projectile, and the shape and character of the projectile at the point of impact, i.e., the nature of the projectile point. Many factors come into play in the formula for the ballistic characteristics of even the most 'primitive' projectiles. For example, a bow-shop at a deer involves the pull of the bow, the weight of the arrow, the relative straightness of the arrow, the character of fletching if any, the range involved, the frontal area and cutting edge of the point, the weight and musculature of the animal, and the point of impact on the animal's anatomy. A cast at the same deer with an atlat1 would involve essentially the same factors, substituting the length and strength of the hunter's arm and the effective length of the throwing board (the distance from the hand grip to the hook) for the pull of the bow.

Flight ballistics of darts and arrows then can be seen to be dependent on numerous factors. The presence or absence of fletching does not seem to be critical. The spearthrower darts used by the modern Australians are not fletched (Gould 1969:98). Both fletched and unfletched darts were used by the ancient Great Basin peoples, as both types have appeared in archeological sites (Heizer 1951: Dalley, in Aikens et a1 1970). The arrows used by ethnographic Bushmen in the Thomas Expedition film "The Hunters" are not fletched, while fletched arrows are the rule in ethnographic 
North America. 01sen $(1967: 124)$ has experimented with both fletched and unfletched types, using Great Basin-type bows and arrows, and has found that both types will work, though the fletched varieties are more accurate.

The straightness of the shaft of a dart or arrow is of course crucial to its flight and accuracy, but as it seems that all "primitive" projectile makers strive for this quality it may be seen as a constant, with any variation resulting from differences in raw material nad the individual skill and patience of the maker.

One factor which is crucial to flight ballistics is balance. In other words, the center of gravity of the projectile must fall at or near the midpoint of its length. This has been confirmed experimentally by Browne (1938) with arrows, and by Spencer (1974) with darts. The weight of a projectile point has considerable influence on the projectile's balance because of its position at the extreme distal end. Spencer (1974:48-51) used a 3-piece, reed-shafted dart replicating the Leonard Rockshelter specimen in his experiments, discovered that too light a point caused the dart to 'nose-up' in an erratic flight pattern. When the point-foreshaft combination weighed the same as the proximal butt--or fletch shaft, the dart flew well. A heavier foreshaft of more dense wood would of course compensate for a light point, at least as regards darts.

Since initial velocity is an important factor in flight characteristics there must be some limit to the total weight of the projectile in either case. Maximum dart weight would be determined by the strength of the hunter's arm and the length of the throwing board. Hill (1948:37-44) found in his experiments that maximum range was obtained with "medium" weight darts. This would indicate that there is some optimum range of dart weight for a given hunter and atlat1, which can be exceeded or under- 
cut only with a resultant loss of efficiency. The upper limit of the optimum range of weight probably is determined by the decrease in velocity as weight increases. The lower limit of the optimum range is probably determined by Sectional Density (essentially, the frontal area divided by the weight), which determines a projectile's "wind-cutting" qualities. At the subsonic velocities generated by atlatls the frontal area is probably less important than weight alone; an analogy might be the distance a ping-pong ball can be thrown by hand as compared to a golf ball. In other words, a very light dart would lack "heft" and thus carry poorly in its trajectory.

Pope (1923) did extensive experiments with the collection of ethnographic bows and arrows of the Lowie Museum. He discovered that arrows seldom exceeded thirty inches in length or two ounces in weight. His experiments with replicas of medieval English war arrows (36 inches, four ounces) showed that such heavy arrows would require a bow six feet six inches 1ong. (It should be noted that Spencer's replica of the Leonard Rockshelter dart weighs about 2 ounces). The Yani Indian Ishi, who worked with Pope in these experiments, made arrows about 30 inches in length and about an ounce in weight, and these arrows were regarded as adequate for deer-size game. (Pope 1923:117) This probably represents the optimum size of arrow for an Ishi-type bow, or a Great Basin bow. The bow made for ethnobotanist Marilyn Couture by Earl Louie, a Burns Paiute, is of similar form and dimension to Ishi's bows, for example. If the thirty-inch, oneounce arrow is the optimum size for a Great Basin type bow, the necessity for shaft balance would put fairly stringent limits on the size of the point used. Too heavy a point would make an arrow unstable, or too slow to penetrate well. Browne (1938) did experiments with a home-made primitive 
bow and points of various weights, and discovered that, by using heavy shafts, he could successfully shoot arrows with heavy points. However, he used a replica of a large Plains-type bow which could be expected to handle heavier arrows than the smaller, 1ighter Great Basin types. Also Browne did not test his bow for penetration on game; such heavy arrows may or may not have sufficient velocity ot achieve the range and penetration necessary for effective hunting.

The problem with using a single variable as an index of function of projectile points is that the other variables, expecially the length and density of the shaft, enter into the ballistic formula, but these parts are usually not preserved. Point weight bears a relation to the total weight of the projectile because of the balance requirement. Neck width seems to reflect the maximum diameter of the foreshaft and can thus be related to the rest of the projectile. The variation in the mean neck width values for dart and arrow points in different cultural areas noted by Corliss may reflect different raw materials (and consequent differences in density), and manufacturing techniques of foreshafts in different areas. The present research was directed to the investigation of the variation of point attributes in a sample from a single cultural area in hopes that the most distinctively bimodal attributes could be isolated in a sample with minimal variation caused by raw material and cultural differences. 


\section{SAMPLING}

The sample of points used in the present research was taken from the collection derived in the course of the archeological recommaissance and testing of the Malheur National Wildlife Refuge, Harney County, Oregon, 1971-1974, under the direction of Dr. Thomas M. Newman of Portland State University. The Malheur National Wildlife Refuge consists of the drainage of the Donnner und Blitzen River, the shallow tule marsh Malheur Lake, and the playa Harney Lake, covering approximately 186,000 acres in the northern Great Basin in southeastern Oregon. It was created as a national wildlife refuge by President Theodore Roosevelt in 1908 because of its significance as a nesting place and stopover for migratory birds. It was also a significant focus of aboriginal habitation, nad over 150 sites were discovered in the course of the archeological reconnaissance. Most sites on the Refuge are surface scatters, badly deflated and showing little or no depth of fill or natural stratigraphy. Sites are concentrated on the margins of the marshy areas and fossil beaches of the playa, though some sites lie on the higher ground overlooking the river valley and marshes. A few rock shelters and rock overhangs were used by aboriginals as habitation or camp sites. Most of the substantial collection of chipped stone artifacts was collected from deflated surface sites by the reconnatssance teams, generally small random samples from each site, though in some cases systematic collections on a grid were made by Dr. Newman's students during Field School sessions. A few test pits were opened in surface sites which showed some depth of fill, and several of the smaller rock overhangs were 
also tested in the course of the work. Both surface and excavated materials are included in the sample.

The bulk of the artifactual material recovered was chipped and ground lithics. Projectile points and fragments, scrapers, drills and utilized flakes of obsidian, other volcanic cryptocrystallines, and chert form the bulk of the chipped stone assemblage. The ground stone assemblage consists mostly of fragmentary manos and metates of vesicular basalt. One small rockshelter yielded tule matting, fragments of basketry, sinew and vegetable cordage, and a sage bark sandal, as well as chipped and ground lithics. All cultural materials from the Refuge can be classified as Desert Culture, typical of the northern Great Basin.

The original sample in this research consisted of the entire collection of complete chipped stone points from all sites from the field seasons 1971-1974. It consisted of 141 points, showing a wide range of form, workmanship, and raw material. All of these points were notched or stemmed forms; the other 30 showed no clearly defined stem. During the course of the work it became necessary to eliminate the stemless forms from the sample because of their missing values. However, they are illustrated and described in the Typology section of this paper.

The first stage in the analysis of the sample was its classification by means of the typology used by Aikens (1970:33-56). The Malheur points showed an excellent fit with the types used by Aikens. It was not necessary to create any new types to accomodate the Malheur sample.

Fagan (1973) has proposed a seriation chronology for the northern Great Basin on the basis of projectile point styles. He posits four periods: IV, 10,000-7,000 B.P.; III, 7,000-5,000 B.P.; II, 5,000-3,000 B.P.; I, 3,000 B.P.-Ethnohistoric. The Malheur points seem to cover this full range of time 
on the basis of style, though the bulk of the points in the sample would fall into periods III and I. In any event it seems that the Malheur sample covers a sufficiently long period of time to include both dart and arrow points.

Three fundamental assumptions are made about the Malheur point sample. First, it is assumed that all of the points in the sample could have been used as projectile tips. This does not of course imply that all of them actually were so used. In any event, the initial selection of the points deliberately eliminated any bifacially worked pieces which were too large, crudely made, or asymmetrical to have served as projectile tips. Also eliminated were any smaller finely worked pieces that were obviously drills. A second assumption, based on seriation dating, is that both dart and arrow points are present in the sample. A third assumption, based on a general knowledge of Great Basin archeology and ethnography, is that no type of stone-tipped projectile other than the dart and the arrow was used in the area during the time period represented by my sample. In other words, I assume that my sample contains dart points, arrow points, and except for mistakes in identification, nothing else. 


\section{TYPOLOGY}

The first stage in the analysis of the Malheur point sample was its classification by named types, following the system used by Aikens (1970) with the Hogup Cave points. This system utilized the named types which have evolved over the years of archeological research in the Great Basin. Named types which show similarities of size, form, workmanship, and temporal affinity are grouped together in series. I selected Aikens' typology because of the excellent fit that was apparent from my preliminary work with the Malheur materials as a student participating in the Malheur project. Jennings (1974:159) has commented upon the general similarity of chipped 11thics from Oregon and Utah Great Basin sites, and my own sample bears this out. It was not necessary to create any new types to accomodate the Malheur sample.

Aikens (1970:50) recognized four series of Great Basin points which represent four cultural/technological traditions, with the individual types representing variant expressions of the basic traditions. These are: Series 1, Pinto; Series 2, Lanceolate; Serles 3, Elko; and Series 4, Small. Series 1 and 4 contain both stemmed and stemless forms. Series 2 includes only stemless types. Series 3 includes only stemmed types. My original sample contained types belonging to all four serles. In the course of the work I had to eliminate the stemless forms from the sample. However, all specimens are considered in this descriptive section.

Various silicious cryptocrystalline rocks were used by the flintknappers of Malheur for chipping projectile points. These are apparently 
of both volcanic and sedimentary origin. The most common raw material is obsidian, a translucent volcanic glass which ranges in color from almost colorless to black, sometimes showing darker bands of gray or red. Other types of rock of apparently volcanic origin were used. These range in color from light gray to black, and in consistency from fine-grained and glassy to coarse-grained and rough. Translucent volcanics were classed as obsidian. All other raw materials of apparently volcanic origin were classed as other volcanic.

Raw materials of apparently sedimentary origin range in color from almost white to a dark caramel brown. These were all classed as chert. Chert was apparently less popular than the volcanic rocks as a raw material for projectile points among the knappers of Malheur, as relatively few points were made from these cryptocrystallines.

Table I summarizes the typological and metric data of the Malheur sample. Representative samples of each type appear in Figures 1 and 2 . 
TABLE I

MALHEUR POINT TYPOLOGY

AND

METRIC DATA SUMMARY

Series 1 Pinto (Little Lake) Points

Pinto Shouldered ( 7 specimens; all other volcanic)

$\begin{array}{lr}\text { Weight: } & .75-5.55 \mathrm{gm} . \\ \text { Neck width: } & 1.13-1.70 \mathrm{~cm} \text {. } \\ \text { Stem thickness: } & .41-.57 \mathrm{~cm} .\end{array}$

Series 2 Lanceolate Points

Humboldt Concave Base (6 specimens; 2 obsidian, 4 other volcanic) Weight: $.85-5.05 \mathrm{gm}$.

Series 3 E1ko Points

Elko Corner Notch (11 specimens; 8 obsidian, 3 other volcanic)

Weight:

Neck width:

$1.15-4.05 \mathrm{gm}$.

Stem thickness: $\quad .35-.47 \mathrm{~cm}$.

E1ko Side Notch (4 specimens; 3 obsidian, 1 other volcanic)

Weight: $\quad 1.30-3.55 \mathrm{gm}$.

Neck width: $\quad .97-1.38 \mathrm{~cm}$.

Stem thickness: $\quad .36-.42 \mathrm{~cm}$.

Elko Eared (14 specimens; 10 obsidian, 4 other volcanic)

Weight:

Neck width:

$.85-6.30 \mathrm{gm}$.

Stem thickness: $\quad .21-.62 \mathrm{~cm}$.

E1ko Split Stem (4 specimens; 3 obsidian, 1 other volcanic)

Weight: $2.10-2.85 \mathrm{gm}$.

Neck width: $\quad .96-1.39 \mathrm{~cm}$.

Stem thickness: $\quad .27-.37 \mathrm{~cm}$.

Northern (Bitteroot) Side Notch ( 4 specimens; 1 obsidian, 3 other volcanic)

Weight:

Neck width:

$1.60-4.70 \mathrm{gm}$.

$1.11-1.66 \mathrm{~cm}$.

Stem thickness: $\quad .27-.54 \mathrm{~cm}$. 


\section{Serles 4 Small Points}

Rose Spring Corner Notch (43 specimens; 25 obsidian, 15 other volcanic, 3 chert)

We1ght:

Neck width:

$.30-2.00 \mathrm{gm}$.

$.35-1.06 \mathrm{~cm}$.

Stem thickness: $.13-.32 \mathrm{~cm}$.

Rose Spring Side Notch (3 specimens; all obsidian)

Weight: $\quad .15-.55 \mathrm{gm}$.

Neck width: $\quad .35-.42 \mathrm{~cm}$.

Stem thickness: $.18-.21 \mathrm{~cm}$.

Eastgate Expanding Stem ( 6 specimens; 5 obsidian, 1 other volcanic)

Weight: $\quad .50-.55 \mathrm{gm}$.

Neck width: $\quad .50-.63 \mathrm{~cm}$.

Stem thickness: $.19-.28 \mathrm{~cm}$.

Eastgate Sp11t Stem ( 3 specimens; 2 other volcanic, 1 chert)

Weight: $\quad .45-.85 \mathrm{gm}$.

Neck width: $\quad .50-.63 \mathrm{~cm}$.

Stem thickness: $.18-.25 \mathrm{~cm}$.

Desert Side Notch ( 4 specimens; 2 obsidian, 2 other volcanic)

Weight:

$.40-1.90 \mathrm{gm}$.

Neck width: $\quad .65-1.05 \mathrm{~cm}$.

Stem thickness: $.18-.23 \mathrm{~cm}$.

Cottonwood Triangular ( 8 specimens; 5 obsidian, 3 other volcanic) Weight: $\quad .40-1.75 \mathrm{gm}$.

\section{Residual Points}

Scottsbluff (1 specimen; chert)

McKean-11ke (2 specimens; both other volcanic)

Wendover Nodular ( 2 spectmens; both cert)

Leaf-shaped ( 7 spectmens; 3 obsidian, 3 other volcanic, 1 chert) 

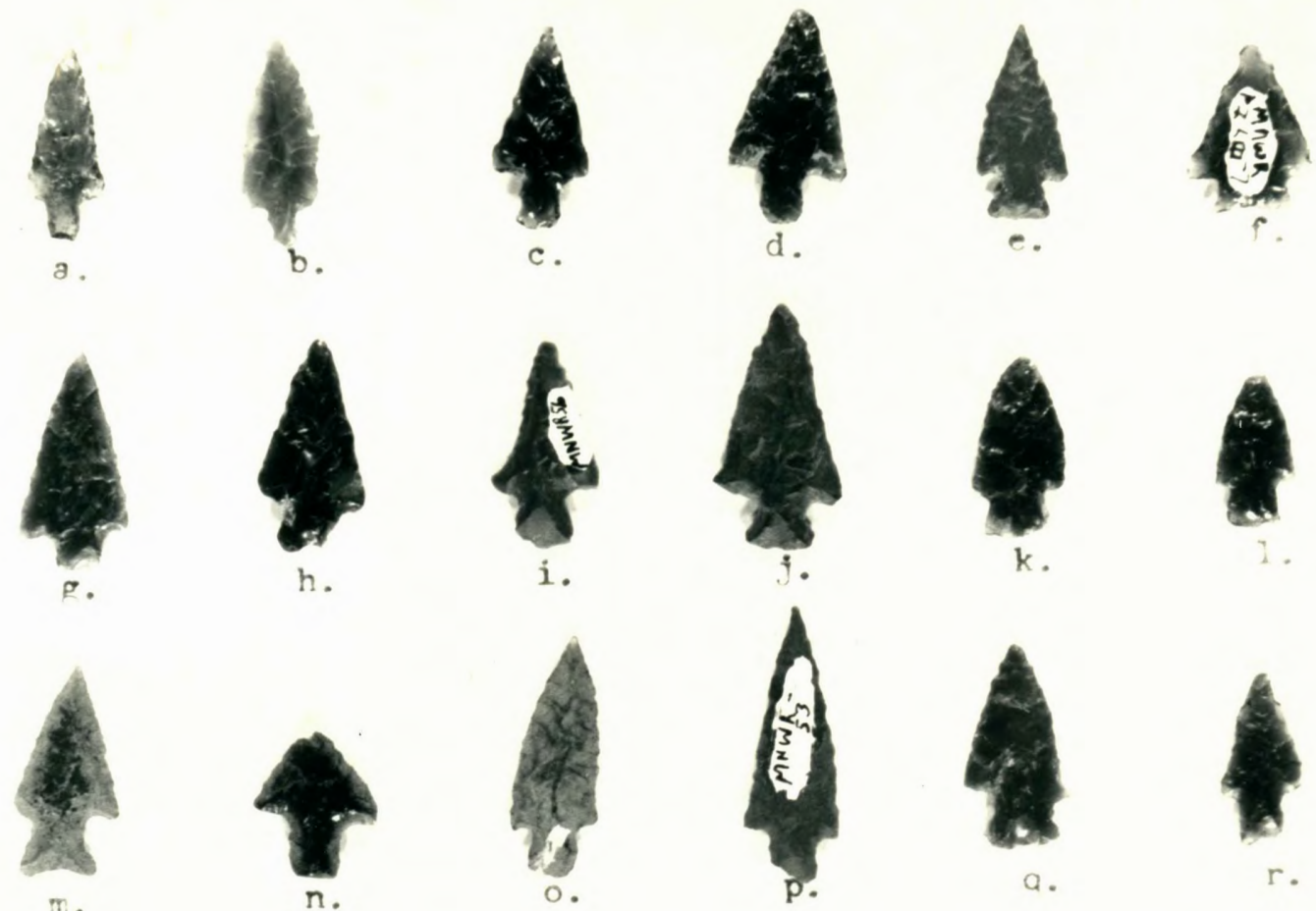

m.
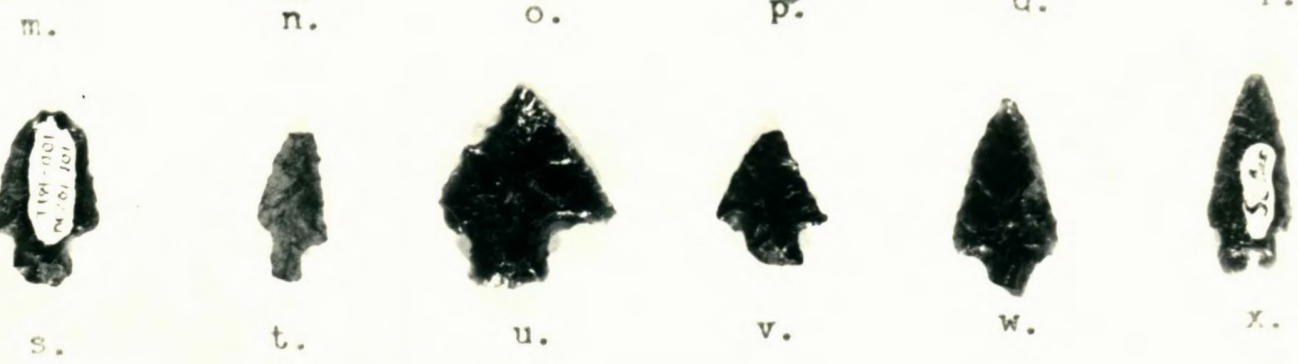

u.

v.
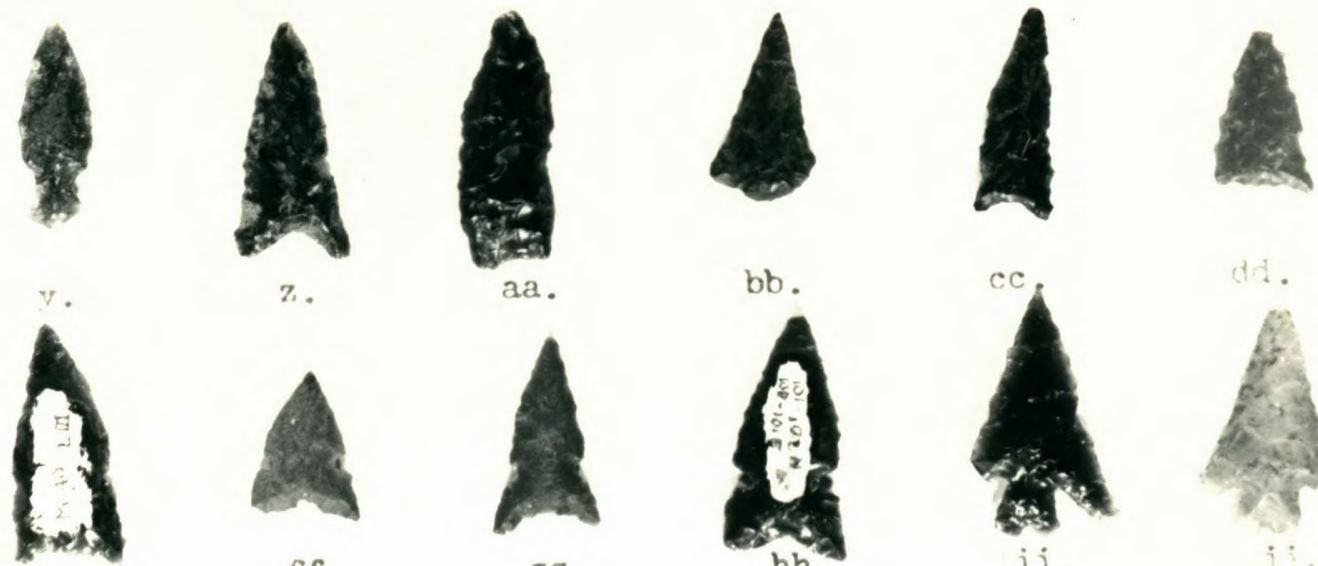

$$
\text { aa. }
$$
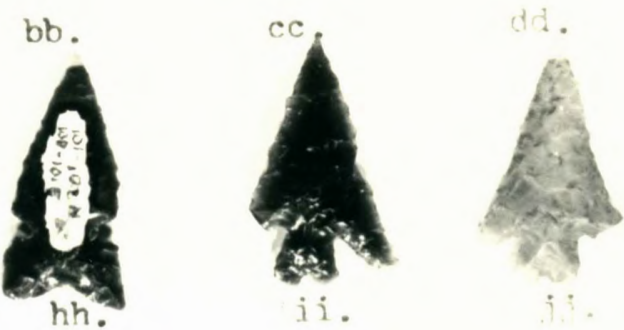

Figure 1. Representative Specimens of Malheur Points, Series 1 


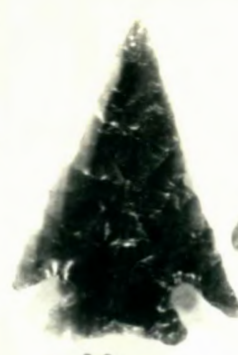

kk.

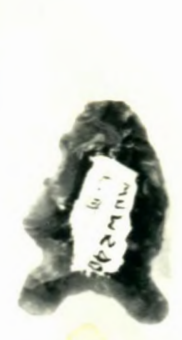

qa.

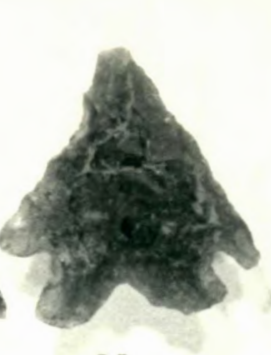

11.

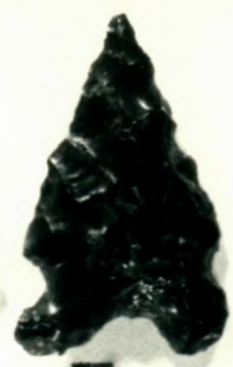

min.
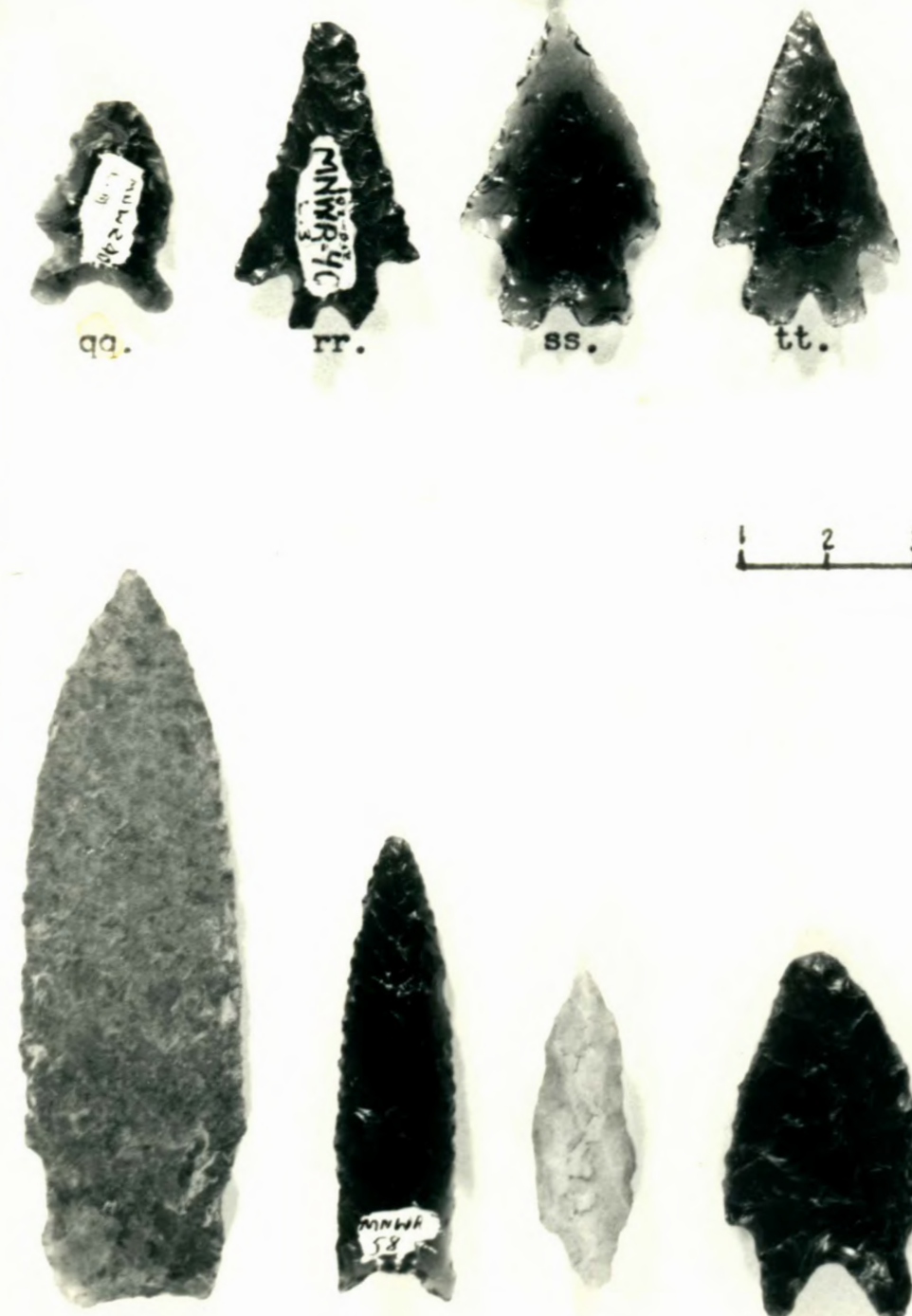

WW.

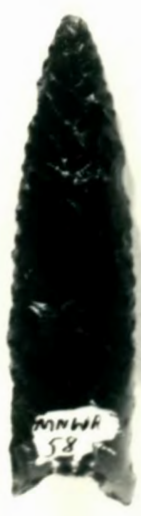

$x x$.

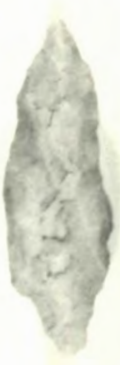

yy.
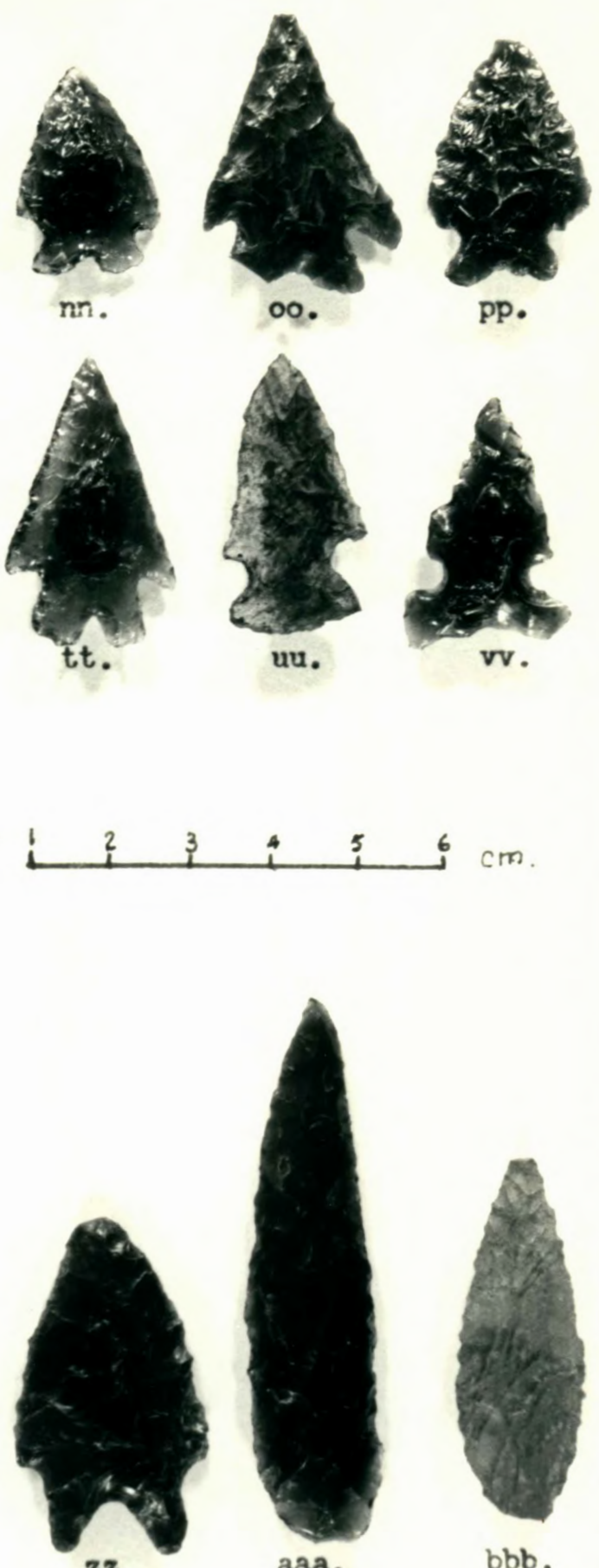

bbb.

Figure 2. Representative Specimens of Malheur Points, Series 2-4 and Residual 
KEY TO FIGURES 1 and 2

Figure 1
a. $-\mathrm{x}$.
Rose Spring Corner Notch
y.
Rose Spring Side Notch
z. - ee.
Cottonwood Triangular
ff. - hh.
Desert Side Notch
ii. - jj.
Eastgate Split Stem

\section{Figure 2}

$\mathrm{kk}$.

E1ko Corner Notch

11. - qq.

E1ko Eared

rr. - tt.

E1ko Split Stem

uu.

E1ko Side Notch

vv.

Northern Side Notch

WW.

Scottsbluff

$\mathrm{xx}$.

Humboldt Concave Base

yy •

Wendover Nodular

zz

Pinto Shouldered

aaa. - bbb. Leaf-shaped

(Points are actual size) 


\section{ATTRIBUTE ANALYSIS}

After the classification by type and series, the points in the sample were weighed and measured for four linear attributes. Points were weighed on a simple chemical balance to .01 gram and measured to $.01 \mathrm{~cm}$. with a Helios dial-type Vernier caliper with needle-pointed jaws. The four linear dimensions or attributes were length, maximum width, neck width, and stem thickness. Neck width is defined as the dimension of the stem resulting from the constriction caused by the bilateral notching of the artifact below the barbs. Stem thickness was measured at the midpoint of the stem on the center line of the artifact. Figure 1 shows how all measurements were taken. The original sample contained leaf-shaped and lanceolate points which lack stems. The measurements for neck width and stem thickness for these points were, of course, not taken. By way of preliminary investigation, frequency histograms were drawn by hand for weight and neck width. Weight showed a strangely skewed distribution, with most members of the sample falling well below the midpoint of the range. Neck width (of the notched types) showed an apparently bimodal distribution. At this point I decided to adapt the sample to computerized analysis. The metric data plus type, a site number, and raw material codes, were transferred to computer cards, one card per artifact. The neck width flelds on cards corresponding to stemless forms were left blank. During the measurement of the stemless forms, I had arbitrarily selected and measured a 'stem thickness' halfway between the point of maximum width and the base, in hopes that this measurement would correspond to the stem 
thickness of the notched forms; this value was entered in the stem thickness field on the cards of the stemless forms. The first stage of the analysis was the generation of histograms, using the BMD05D program of the UCLA Biomedical program package. Several runs were made, juggling the base scales of the histograms in an attempt to 'flush out' any apparent bimodality. It soon became apparent that the stemless forms were causing trouble. My arbitrary basal measurement tended to make the stem thickness curve appear as a normal distribution; when the stemless pieces were left out, this attribute appeared to be bimodal. The computer read the blank neck width fields on these cards as zero. This caused no problem in simple histogram generation, as the column of zero values could be ignored. However, I decided to use the sample with a clustering-type program, and the inclusion of these pieces would have complicated that process needlessly. I followed the lead of Corless (1972) and eliminated these points from the sample. This reduced the sample size from 141 to 111. A new set of histograms was generated using only the notched forms. (Figure 3-9) The BMD13D t-test program was utilized to test the apparently bimodal distributions shown in the histograms (Table 2). A summary of the results of the histogram and t-test analysis for each attribute follows.

Weight

This attribute was selected because of its previous use by Fenenga as a clue to projectile point function. The histogram shows a skewed-normal type distribution, with almost all points falling to the left of the midpoint of the range. It is also apparent that the range of weights in the sample is great. This histogram could be interpreted in several ways. It 
is apparent that most of the sample welghs less than 2.8 grams, but a significant part of 1 t is heavier than that. There is no clear 'valley' of a distinctively bimodal distribution. Since any cut point for the t-test would be arbitrary in a case 1lke this, I tried the 2-gram value cited by Cressman for the Catlow Valley points. The critical value for $t$ at the $99.9 \%$ level for this sample size 1s 3.373 . The $t$ value calculated for weight in my sample is 5.04 , indicating that the means of the two groups created by the arbitrary cut were significantly different, and the strong possibility of two groups within the sample. It is also possible that the great range of weights in the sample caused the apparent significance of the $t$ value, and $I$ do not consider the $t$ value of weight as conclusive proof that weight is a good indicator of point function.

St111, the shape of the curve suggests that it may represent two normal distributions with their tails overlapping. In other words, there may be an optimum welght range for arrow points with a mean value of about 1 gram, and an optimum weight range for dart points with a mean of about 3.5 grams. In previous discussions I have suggested that minimum point weight is less critical than maximum point weight, so an overlap of this sort should not be too surprising. In any event, I would be hesitant to use weight alone as the sole index of functional class for Great Basin points.

\section{$\underline{\text { Length }}$}

This attribute was selected because of its previous use by Fenenga. He found no significant bimodality, but I wanted to re-test his refection of it with a sample of points from a limited geographical and cultural area. 
It shows a more or less normal distribution, and although I did try the ttest with an arbitrary cut point which produced a significant value at the $99.9 \%$ level (6.50), I must agree with Fenenga that this attribute cannot be used as an index for distinguishing dart points from arrow points.

Maximum Width

This attribute was used by Fenenga (with no results), and used here mostly as a re-test of Fenenga's conclusion. Surprisingly, it appears to show a bimodal distribution, with a break at $1.3 \mathrm{~cm}$. However, it does not appear to be segregating the sample into dart points and arrow points, despite the high $t$ value of 14.58 ( 3.373 is the critical value at the $99.9 \%$ leve1) when $1.3 \mathrm{~cm}$. was used as the cut point. I pulled out the cards showing this maximum width value or less, and discovered that all were Rose Spring Corner Notch (Series 4, Period I, post-3,000 B.P.) and in fact were the tiniest examples of this type of small point. All were less than .85 grams in weight. This bimodality is either fortuitous, or represents some optimum of reduced impact area to allow penetration with the smallest, lightest possible arrow. A third possibility is that these points actually do represent another functional class of artifacts--toys. The Hogup materials include fragments of an extremely tiny arrow which Dalley has so classified (Dalley, in Aikens et al 1970:186). Perhaps at least some of these very small points of the Malheur sample were used to tip toy arrows.

Neck Width

This attribute was first used by Forbis (1960), and has subsequently been utilized by Binford and Papworth (1962), Wyckoff (1964), and Corliss (1972) as an index for distinguishing dart points from arrow points. Its 
use is based upon the assumption that this dimension limits the maximum size of the foreshaft and thus reflects the size and weight of the rest of the projectile. For the Malheur sample, it shows a markedly bimodal distribution, with a strong break at $0.8 \mathrm{~cm}$. Using that figure as the cut point, the sample yields a $t$ value of 17.81 , the highest of any variable tested and greatly exceeding the critical value of 3.373 (at the 99.9\& 1eve1). That would indicate that neck width as a good index of point function.

As a cross check to the strong bimodality of this variable, I segregated the card deck on the basis of a $0.8 \mathrm{~cm}$. neck width cut and then referred to the type codes of the cards of the respective groups. Only two typologically ancient points (both frregular Wendover Nodular types) fell in the 'small' group. No typologically recent points fell in the large group. It seems this variable could be used effectively as a single-attribute index. It would be especially useful with a sample of fragmentary points which could not be measured for weight of other maximum dimensions.

Stem Thickness

I selected this attribute myself. I reasoned that, if neck width limited the maximum diameter of the foreshaft, a measurement of the thickness of the stem would reflect the limit to the minimum diameter of the foreshaft. Since foreshafts were slotted to accomodate the point stem, the foreshaft must exceed the stem thickness so that a wall remains to support the stem. Selection of the midpoint of the length of the midpoint of the length of the stem was arbitrary; however, the stems in my sample seemed in general to be fairly uniform in thickness, tapering abruptly at 
the very base to an edge, so this arbitrary measurement seemed appropriate. It was difficult to measure this dimension on points with short stems, and the measurements of this variable probably contain more observer error than the others. Still, stem thickness showed clear bimodality with a break at about $0.3 \mathrm{~cm}$. This value was used as a $t$ cut point, producing a $t$ value of 16.51 , exceeding the critical value for $t$ of 3.373 at the 99,9\% level. This would appear to be a more useful single-attribute index of point function than weight, but less useful in that role than neck width. In addition to the five original variables, I generated two more variables using the transgeneration feature of the BMD05D program. These were length divided by maximum width (Shape) and the product of maximum width and stem thickness (Frontal Index). Histograms for these transgenerated variables appear in Figures $7-8$.

Shape

This variable was used to test the hypothesis, generated subjectively during the typological classification, that the older type points are shorter in relation to their length than the more recent types. I had hoped that this change would be shown by a bimodal distribution and serve as an index of age and function. The distribution is more or less normal, and a hand claculation of this variable showed that there was no particular relationship between this ratio and type. No t-test was done for this variable.

Frontal Index

This variable was generated and plotted because I hoped it might serve as a rough index of a point's frontal area. It shows bimodality, but as both of the component variables were bimodal, this is netther surprising 
nor necessarily significant. A hand check of the frontal index value and typological age showed only a rough correlation between type and this variable. No t-test was performed for this variable. 
TABLE II

T-TEST RESULTS

Yariable

1. Weight

2. Length

B. Maximum width

4. Neck width

5. Stem thickness
Cut Point

2.0

2.3

1.3

0.8

0.3
Value of $t$

5.04

6.50

14.58

17.81

16.51

Critical value for $t$ at .001 level for a sample of $120=3.373$ 


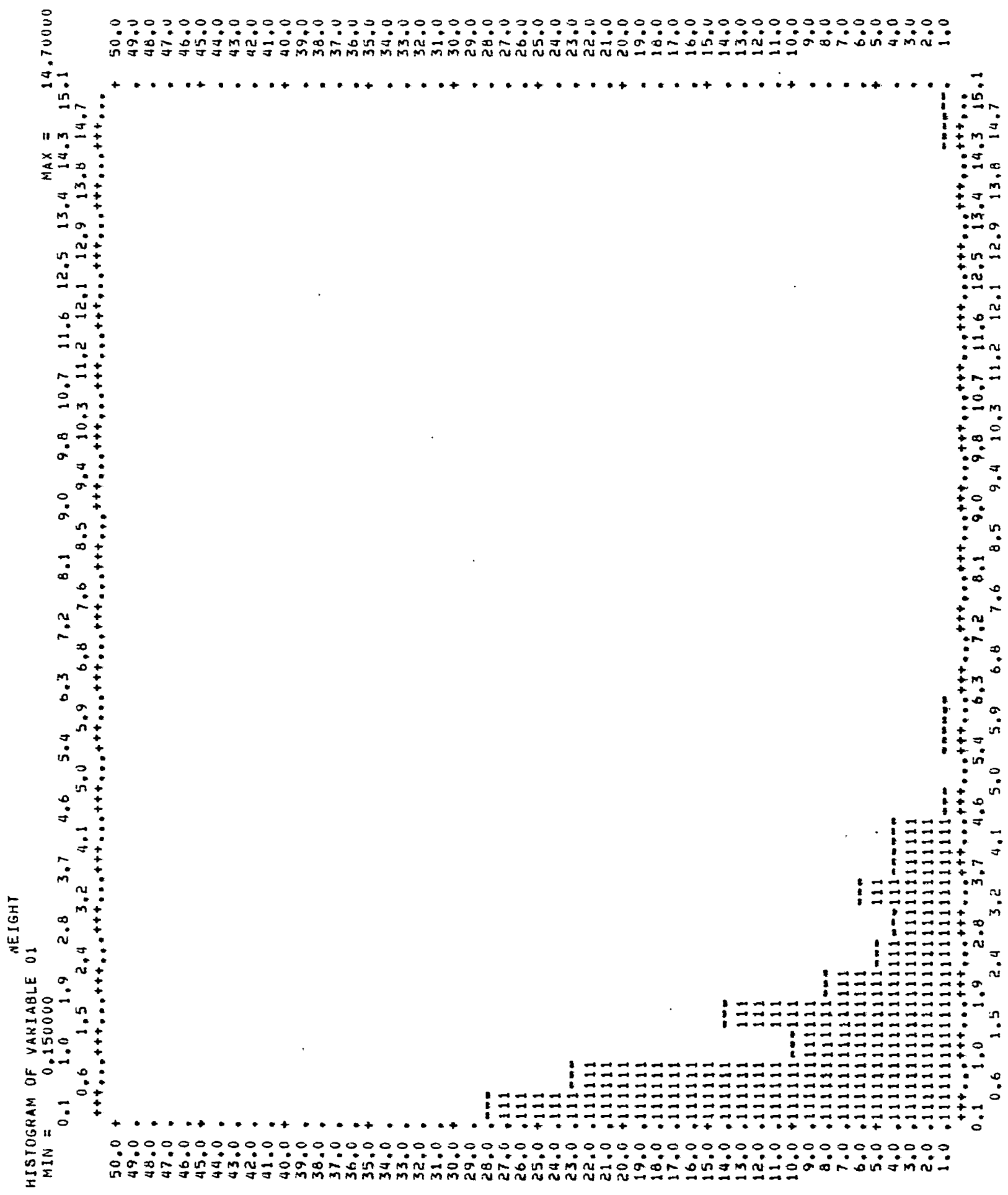

Figure 3. Histogram of Weight 


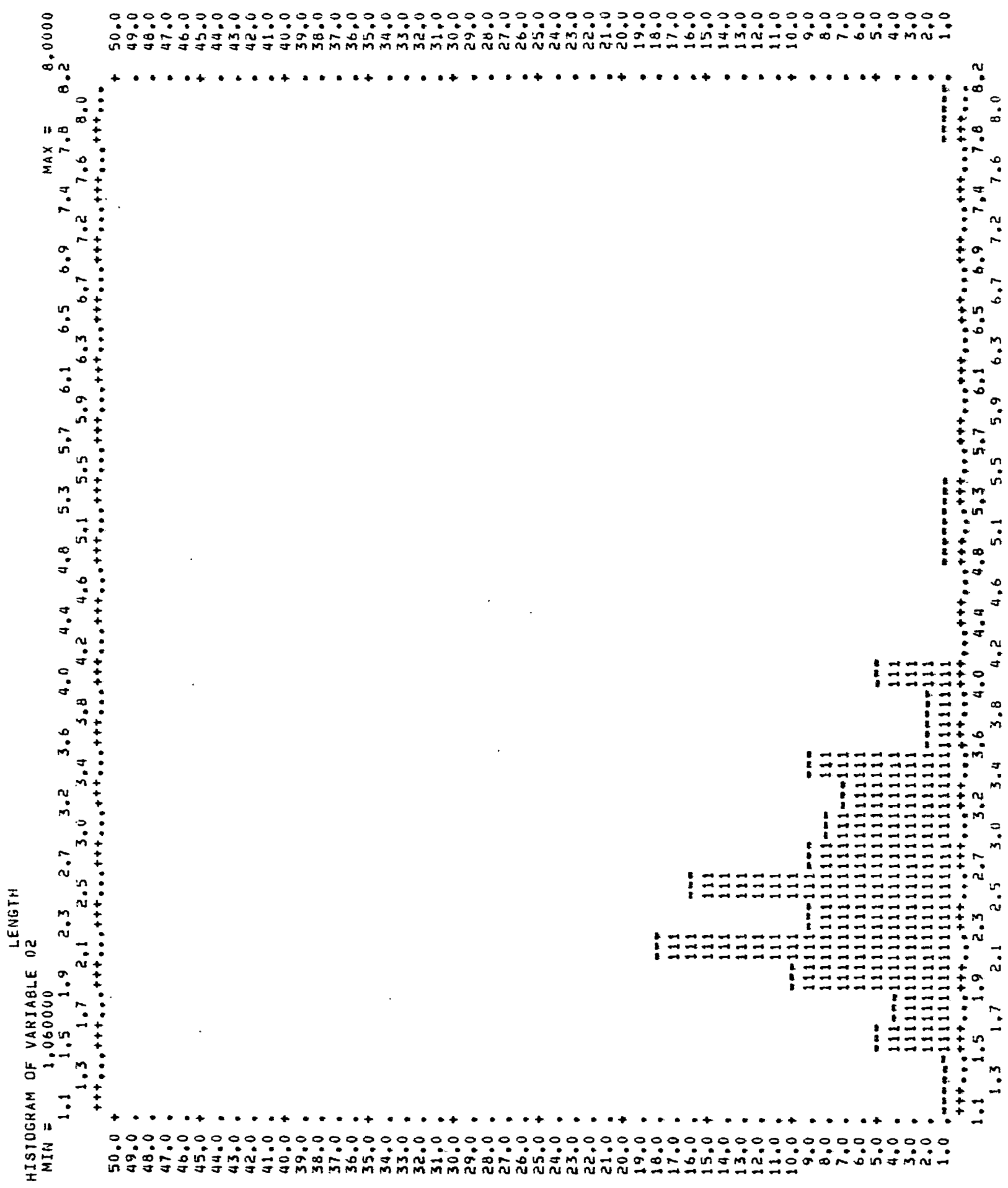

Figure 4. Histogram of Length 


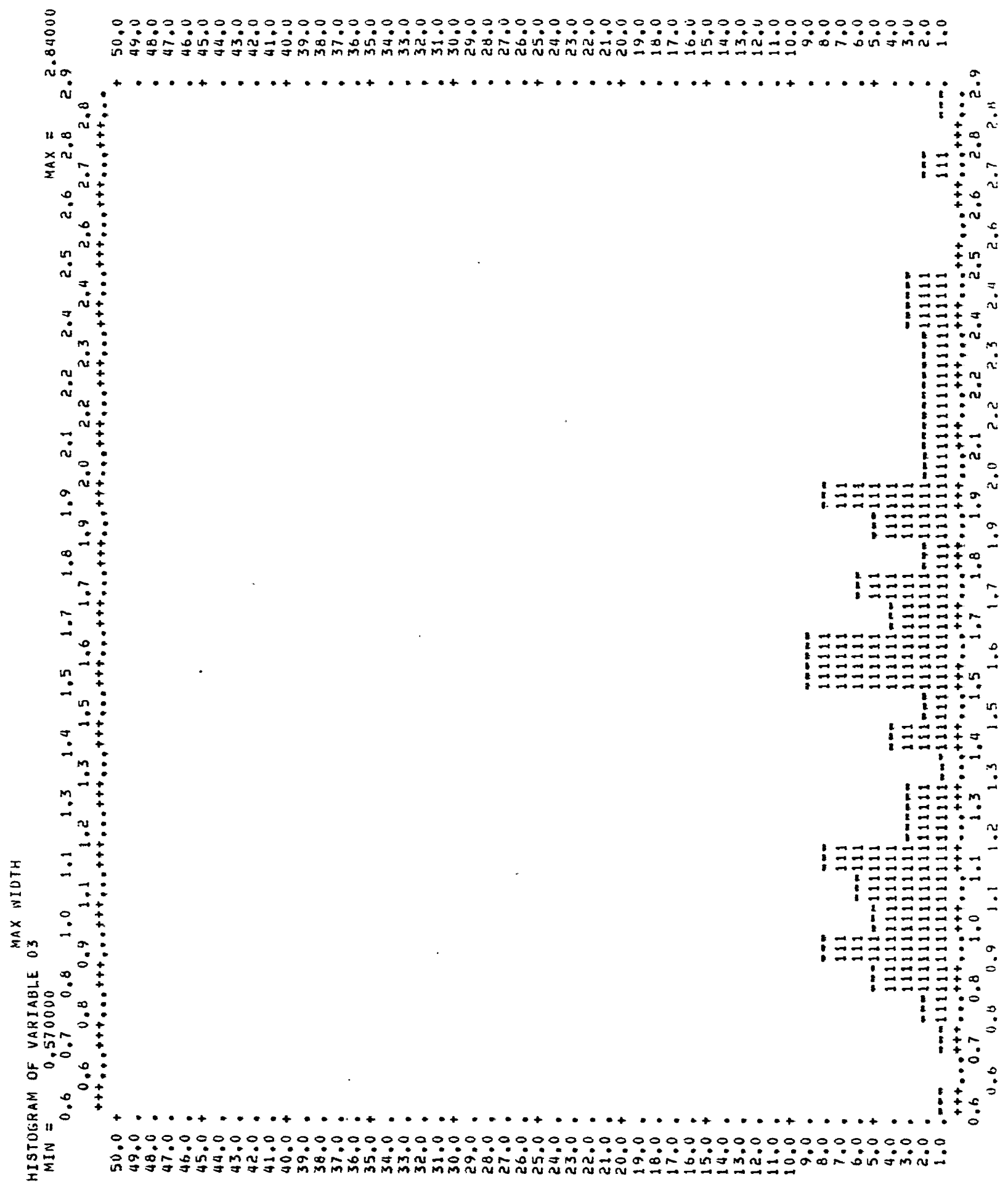

Figure 5. Histogram of Maximum Width. 


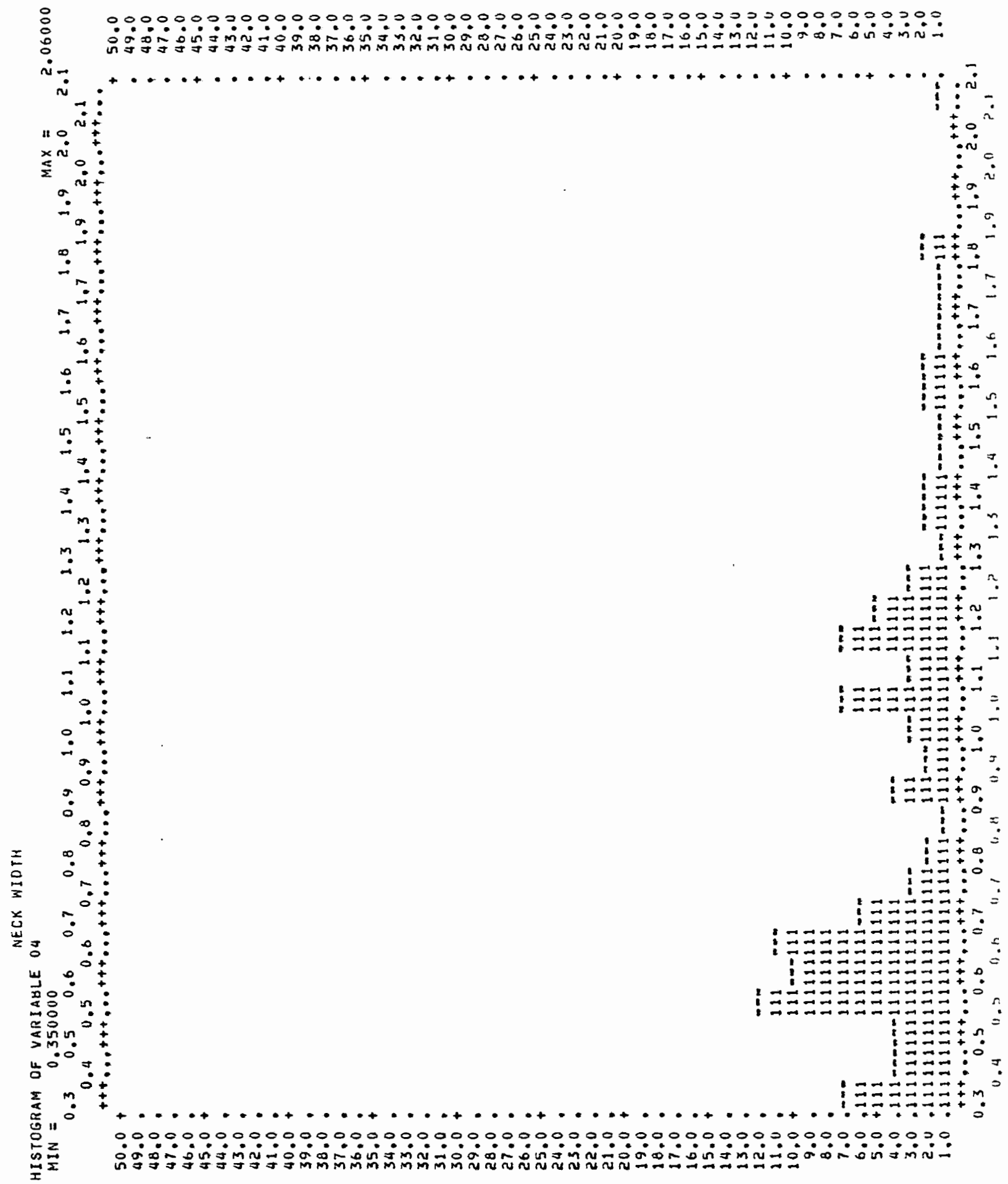

Figure 6. Histogram of Neck Width 


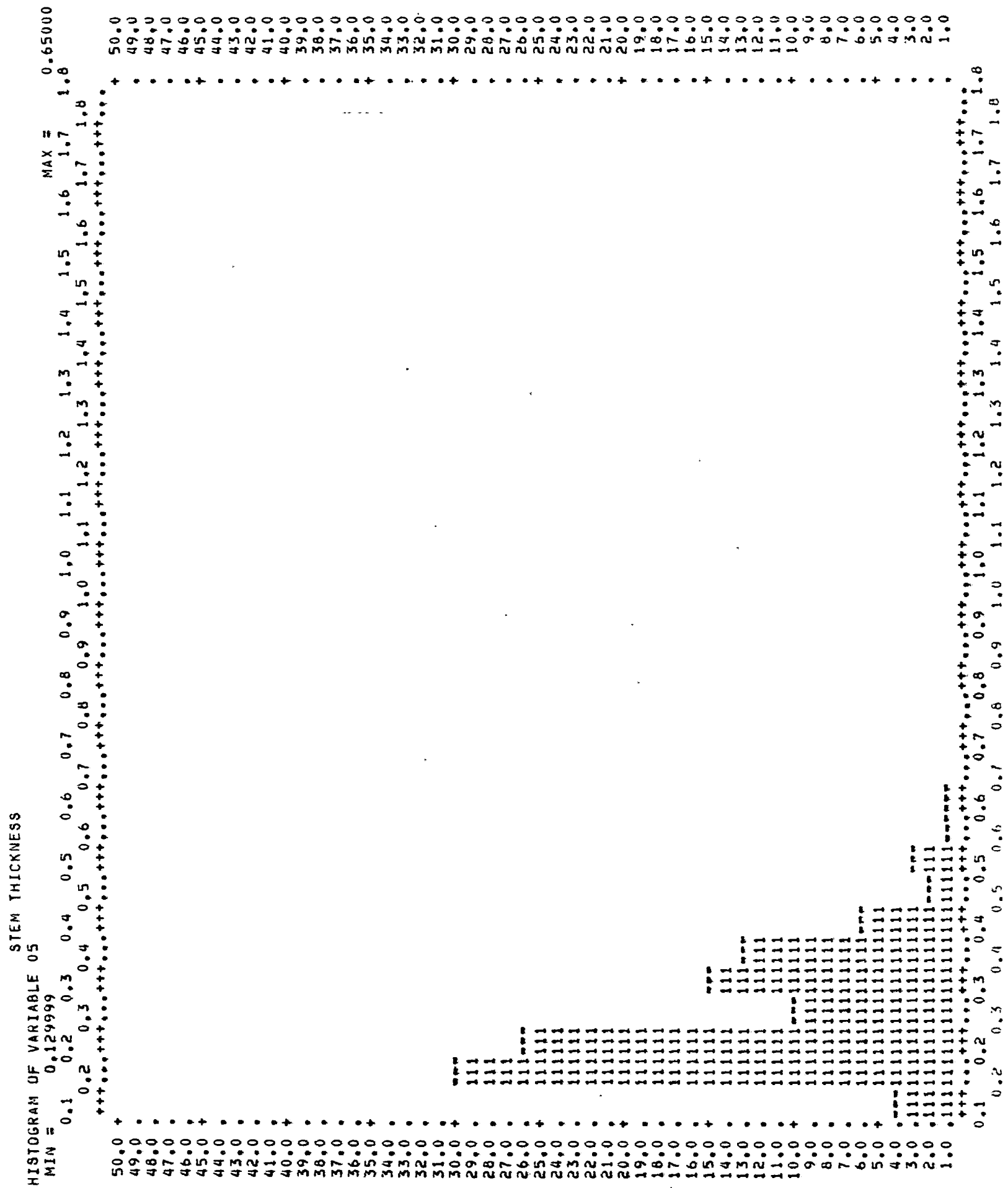

Figure 7: Histogram of Stem Thickness 


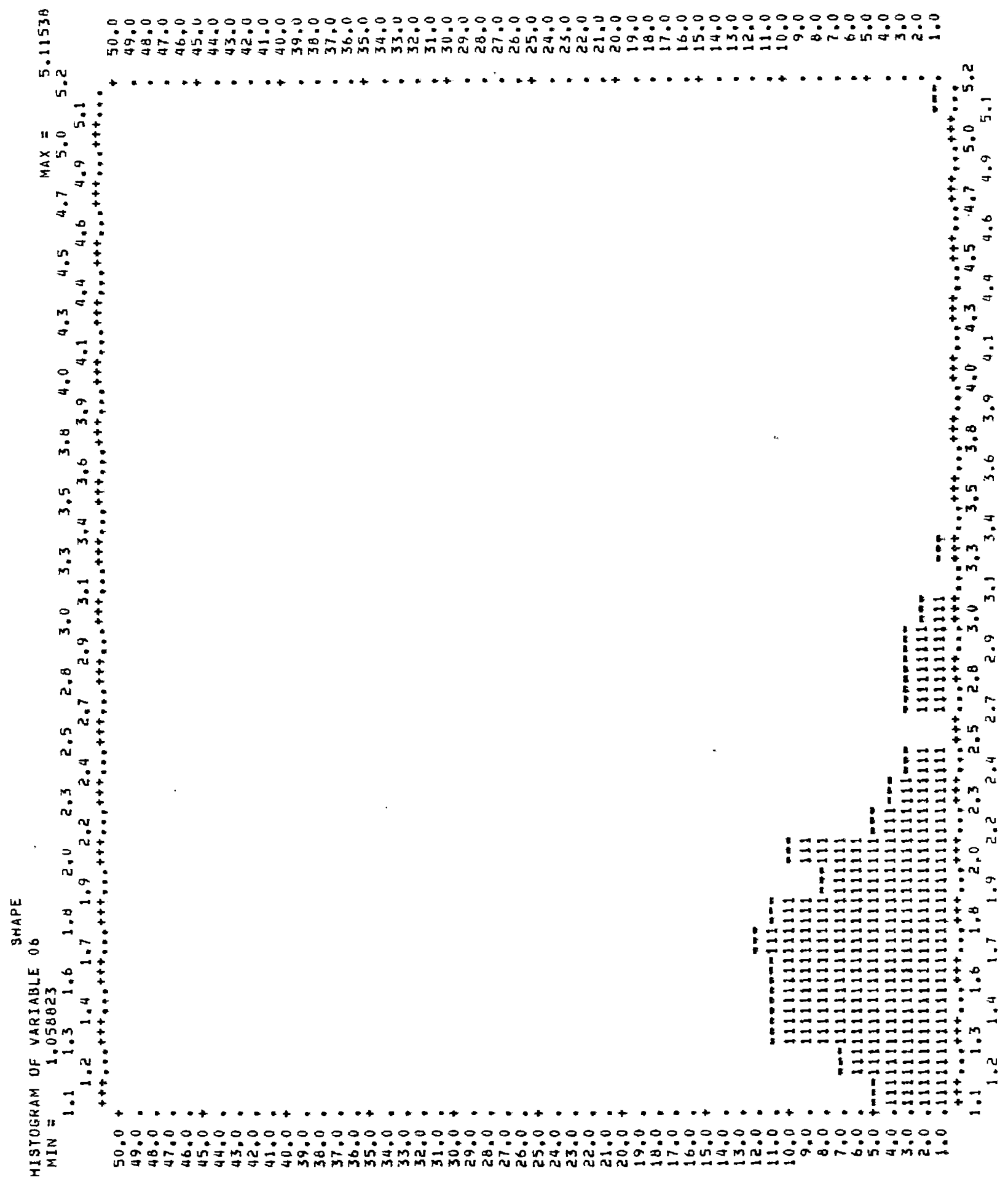

Figure 8. Histogram of Shape (Length/Width Ratio) 


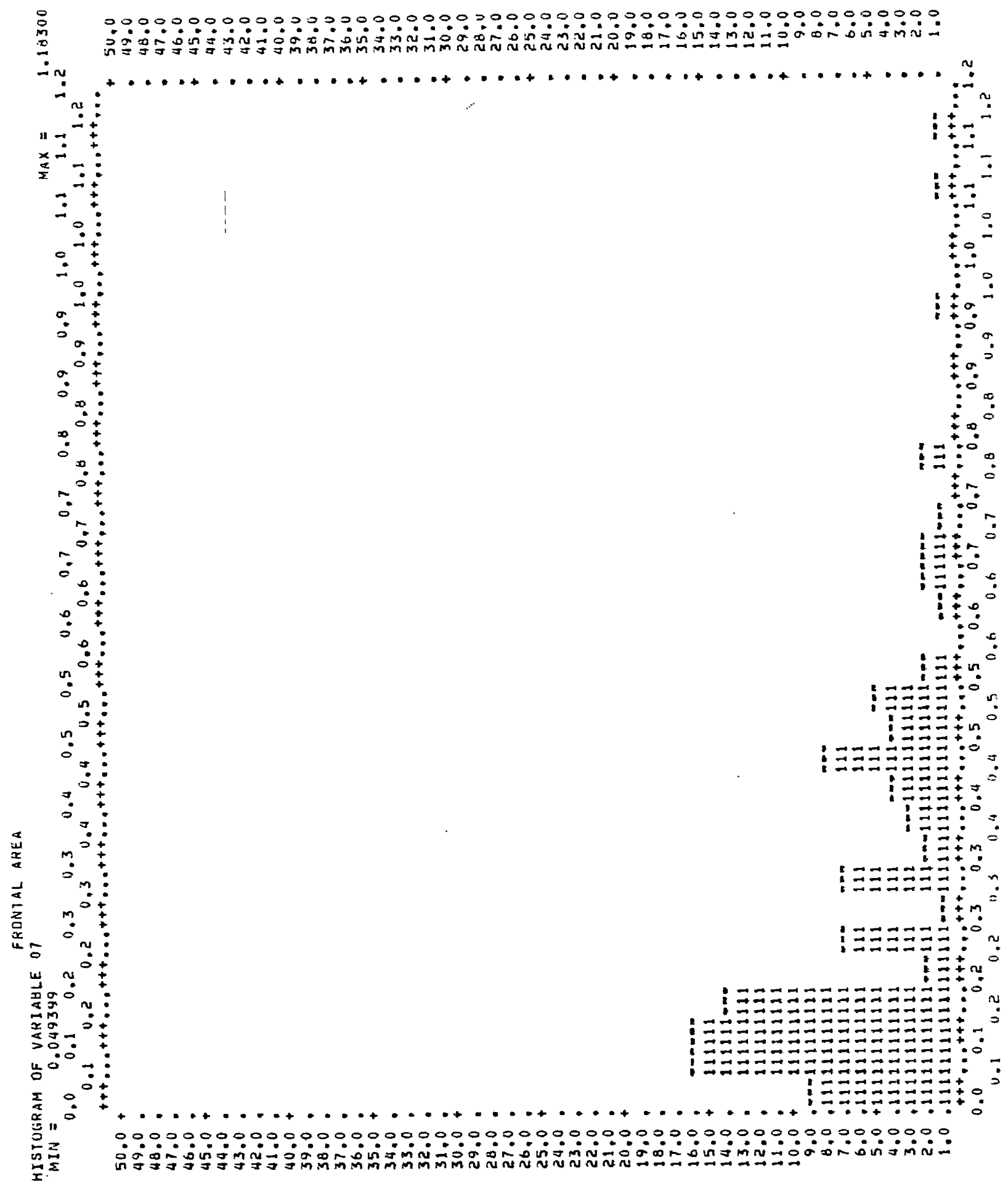

Figure 9. Histogram of Frontal Area (Maximum Width $\mathrm{x}$ Stem Thickness) 


\section{K-MEANS ANALYSIS}

The consideration of the variables singly showed significant bimodality of three (apparently) functionally independent variables: weight, neck width, and stem thickness. I consider these to be functionally independent for two reasons. First, all can be shown to reflect something functionally relevent to the complete projectile, i.e., each variable sets some limit on the dimensions of the entire artifact. Second, there is no necessary mechanical relationship between them, i.e., it is possible to make a point with a narrow neck and a thick stem, or vice versa, and weight can be varied by modifying the maximum dimensions of length, width and gross thickness without affecting the basal modifications of neck width and stem thickness. Because these three variables all seem to reflect something about the size and weight of the projectile, but can be varied independently by the maker, I consider that the use of a single varialbe, no matter how strongly bimodal its distribution might be, as an index of functional class (dart or arrow point) would be less efficient than an index which uses several independent variables considered simultaneously. I attempted to use a multivariate clustering-type analysis on the Malheur sample.

I selected the K-means test for this purpose because it does not require the a priori formation of the sample into groups. This method has been applied to samples of chipped-stone artifacts by Hodson (1972). Basically, it is a method for searching for patterns or homogeneous clusters In a heterogeneous sample of individuals, where each individual has been measured for one or more characteristics or attributes. The K-means 
algorithm uses six basic steps. After the user selects the number of clusters desired, the sample is divided into two groups of as close to equal numbers as possible. Second, the mean for each variable for each groups is computed. Third, the Euclidean distance from the mean of variable 1 in Group 1 of a randomly selected individual is computed, followed by the same computation with regard to the mean of Group 2. The individual is assigned to the group for which the distance is smallest. The individual may oscillate from group to group as the distance based on each variable is calculated. When all the distances based on the variables of the first individual are calculated, the next individual is considered. If the first individual has moved from one group to the other, the means of the two groups are recalculated. Fourth, a second individual is selected and the process is repeated, and a third individual, and so forth. Fifth, when no individual moves (or a specified number of iterations has been performed) the two groupd contain the "correct" individuals, i.e., the distances between the groups have been maximized. Sixth, the total sample is recombined into one group, arbitrarily divided into three groups, and the entire process repeated. This may be repeated for four, five, six, or any number of groups less than the number of individuals in the sample.

The $\mathrm{K}$-means program I used in this work allows the user to specify a maximum number of possible clusters expected. The program calculates the results for the maximum number of clusters and all numbers of clusters less than the maximum and greater than zero. The printout identifies the cluster members, their individual distance from the cluster center, and the means distance of all cluster members to the cluster center, for each cluster. Generally the user of this pragram does not know the optimum number of clusters in the sample. The optimum number of clusters can be 
estimated by, among other things, the Sum of the Squared Error values of the clusters.

In my case, I had assumed that there were only two clusters in the sample, dart points and arrow points. In a sense I attempted to use the K-means as a test of my variables as indices of point function. Because I knew of only two cultural classes of stone-tipped projectiles in the Great Basin, I hoped to discover the variables of points which would yield the maximum differentiation between the two groups consonant with the cultural considerations for two clusters. At the same time, I hoped that the $\mathrm{K}$-means test would allow me to test my assumption by forming more clusters than I believed culturally possible or likely. Unfortunately, the K-means program proved difficult to run on the PSU Harris 220 computer, and only one successful run was made before technical problems forced removal of the computer. The results were promising but inconclusive. Numerical results are summarized in Table 3.

The K-means program I used has a weighting feature whereby the variables may be weighted against each other by whole number values. In my one successful run, I used all five variables weighted equally. I selected a maximum number of four clusters. The four-cluster results showed no apparent relationship to anything I was seeking, 1.e., group membership seemed random with regard to function. I could find no cultural basis for four groups of points within the sample on the basis of ethnographic data or typology.

The three-cluster and two-cluster results were surprisingly similar. In the former, the third or "largest" cluster contained only two individuals, the largest and heaviest points in the sample. It was apparent that the great range of weights in the sample (from .15 to nearly 15 grams) was 
causing trouble, and that weight, the least bimodal of the three functiona1 variables, was having the greatest effect on the clustering. This is undoubtedly due to the high variance of weight and the effect of variance on "distances". The inclusion of the two maximum dimensions of length and width probably compounded this problem. The two largest members of the sample are probably not points at all, but rather knives or the tips of thrusting spears. In this sense, the K-means test served its purpose as a cross-check on my original assumption that the sample contained only dart and arrow points.

The two-cluster results were identical to the three-cluster results except that the two giant "points" were subsumed into the second or "large" group of the two-cluster results. These results show the same effect of the high variance in weight and the effects of high variance on measures of "distance". The "smal1" group probably has too many members and the "large" group probably has too few. The two-cluster K-means results did not do as good a job of segregating the sample into two functional classes as did neck width alone, with nine typologically ancient points falling into the "small" cluster.

Stil1, the method holds promise, and I have no reason to reject my assumption that segregating the sample on the basis of several functionally independent variables would not be more efficient than using a single index variable. I would propose that the $\mathrm{K}$-means test, using the variables of weight, neck width, and stem thickness only and weighted as follows: weight, 2; neck width, 8; stem thickness, 8; would segregate the sample into its functional groups reliably. The weighting factors represent a relationship I had ignored--volume (and therefore weight) increases as the function of the cuble of a linear dimension. Use of the 2:8:8 weighting 
should equalize the effects of the three variables in the $\mathrm{K}$-means test. Another possibility might be some other transformation of the variables (e.g., logarithmic) which would stabilize the variables and render them independent of their means. 
TABLE III

K-MEANS RESULTS

\section{Clusters}

First of 2 clusters; 88 elements; average distance to cluster center $=$ 0.915661

$\begin{array}{lccccc}\text { Variable } & \text { Mean } & \text { S.D. } & \text { Minimum } & \text { Maximum } & \text { Variance } \\ \text { Weight } & 1.0959 & 0.70834 & 0.15 & 2.75 & 5.0174 \\ \text { Length } & 2.4655 & 0.53261 & 1.06 & 3.70 & 2.8367 \\ \text { Maximum width } & 1.3961 & 0.38827 & 0.57 & 2.35 & 1.5076 \\ \text { Neck width } & 0.7431 & 0.27967 & 0.35 & 1.66 & 0.78217 \\ \text { Stem thickness } & 0.2681 & 0.08238 & 0.13 & 0.51 & 0.0679\end{array}$

Second of 2 clusters; 23 elements; average distance to cluster center = 2.21873

$\begin{array}{lccccc}\text { Weight } & 4.8283 & 3.2044 & 2.80 & 14.70 & 102.68 \\ \text { Length } & 4.1917 & 1.3562 & 2.88 & 8.00 & 18.393 \\ \text { Maximum width } & 2.1965 & 0.3860 & 1.04 & 2.84 & 1.4901 \\ \text { Neck width } & 1.4278 & 0.3135 & 0.70 & 2.06 & 0.98254 \\ \text { Stem thickness } & 0.4152 & 0.1149 & 0.21 & 0.65 & 0.13199\end{array}$

3 Clusters

First of 3 clusters; 76 elements; average distance to cluster center = 0.745988

\begin{tabular}{|c|c|c|c|c|c|}
\hline Variable & Mean & S.D. & Minimum & Maximum & Variance \\
\hline Weight & 0.89987 & 0.52873 & 0.15 & 2.10 & 2.7955 \\
\hline Length & 2.3361 & 0.43927 & 1.06 & 3.41 & 1.9295 \\
\hline Maximum width & 1.3234 & 0.34741 & 0.57 & 2.02 & 1.2069 \\
\hline Neck width & 0.70026 & 0.26653 & 0.35 & 1.66 & 0.7104 \\
\hline Stem thickness & 0.25500 & 0.076463 & 0.13 & 0.51 & 0.0585 \\
\hline
\end{tabular}


Second of 3 clusters; 33 elements; average distance to cluster center $=$ 1.13499

$\begin{array}{llllll}\text { Weight } & 3.3273 & 1.0356 & 1.65 & 6.30 & 10.725 \\ \text { Length } & 3.6345 & 0.6072 & 2.79 & 5.32 & 3.6863 \\ \text { Maximum width } & 2.0500 & 0.3843 & 1.04 & 2.84 & 1.4766 \\ \text { Neck width } & 1.2464 & 0.3078 & 0.55 & 1.82 & 0.94711 \\ \text { Stem thickness } & 0.3809 & 0.0947 & 0.21 & 0.62 & 0.08977\end{array}$

Third of 3 clusters; 2 elements; average distance to cluster center $=$ 0.225056

$\begin{array}{lrrrrr}\text { Weight } & 14.650 & 0.070711 & 14.60 & 14.70 & 0.0500 \\ \text { Length } & 7.990 & 0.014142 & 7.98 & 8.00 & 0.0020 \\ \text { Maximum width } & 2.5750 & 0.24749 & 2.40 & 2.75 & 0.6125 \\ \text { Neck width } & 1.9400 & 0.16971 & 1.82 & 2.06 & 0.2880 \\ \text { Stem thickness } & 0.5950 & 0.07778 & 0.54 & 0.65 & 0.0605\end{array}$

\section{Clusters}

First of 4 clusters; 54 elements; average distance to cluster center $=$ 0.510020

$\begin{array}{lccccc}\text { Variable } & \underline{\text { Mean }} & \text { S.D. } & \text { Minimum } & \text { Maximum } & \text { Variance } \\ \text { Weight } & 0.60167 & 0.23433 & 0.15 & 1.15 & 0.54912 \\ \text { Length } & 2.18150 & 0.39425 & 1.06 & 2.97 & 1.5543 \\ \text { Maximum width } & 1.19410 & 0.3029 & 0.57 & 1.88 & 0.91776 \\ \text { Neck width } & 0.57778 & 0.14927 & 0.35 & 1.04 & 0.22282 \\ \text { Stem thickness } & 0.22074 & 0.04282 & 0.13 & 0.34 & 0.018334\end{array}$

Second of 4 clusters; 34 elements; average distance to cluster center $=$ 0.646789

$\begin{array}{llllll}\text { Weight } & 1.8809 & 0.44722 & 1.15 & 2.75 & 2.0000 \\ \text { Length } & 2.9191 & 0.39272 & 2.25 & 3.70 & 1.54230 \\ \text { Maximum width } & 1.7171 & 0.27771 & 1.12 & 2.35 & 0.77124 \\ \text { Neck width } & 1.0056 & 0.2339 & 0.55 & 1.66 & 0.54710 \\ \text { Stem thickness } & 0.34324 & 0.0739 & 0.22 & 0.51 & 0.05459\end{array}$


Third of 4 clusters; 21 elements; average distance to cluster center $=$ 1.00896

\begin{tabular}{|c|c|c|c|c|c|}
\hline Weight & 3.8929 & 0.85386 & 2.80 & 6.30 & 7.2907 \\
\hline Length & 3.8300 & 0.66568 & 2.88 & 5.32 & 4.4313 \\
\hline Maximum width & 2.1605 & 0.38100 & 1.04 & 2.84 & 1.4516 \\
\hline Neck width & 1.3790 & 0.27912 & 0.70 & 1.82 & 0.7791 \\
\hline Stem thickness & 0.3981 & 0.10333 & 0.21 & 0.62 & 0.1068 \\
\hline \multicolumn{6}{|c|}{$\begin{array}{l}\text { Fourth of } 4 \text { clusters; } 2 \text { elements; average distance to cluster } \\
\quad 0.225056\end{array}$} \\
\hline Weight & 14.650 & 0.07071 & 14.60 & 14.70 & 0.0500 \\
\hline Length & 7.990 & 0.01414 & 7.98 & 8.00 & 0.0020 \\
\hline Maximum width & 2.575 & 0.24749 & 2.40 & 2.75 & 0.6125 \\
\hline Neck width & 1.940 & 0.16971 & 1.82 & 2.06 & 0.2880 \\
\hline Stem thickness & 0.595 & 0.07778 & 0.54 & 0.65 & 0.0605 \\
\hline
\end{tabular}




\section{CONCLUSIONS}

Four conclusions can be drawn from the present research. First, weight and neck width both showed significant bimodality, confirming the previous work of Fenenga (1953) and Forbis (1960) as to the functional significance of these attributes in distinguishing dart and arrow points in archeological assemblages.

Second, a new attribute, the thickness of the stem at the midpoint of its length, also shows bimodality and is in all likelihood another variable which can be linked to probable point function.

Third, maximum width shows bimodality but this is probably the reflection of some sub-class of arrow points, either a specialized, highpenetration type arrow for certain game or conditions, or toys. It is also possible that this bimodality represents a temporal distribution. Forbis (1961) found that later arrow points were smaller than earlier arrow points in his Alberta site. Lacking strong temporal controls over my sample, I cannot at this point say if this bimodality represents a functional or stylistic variation.

Fourth, K-means analysis shows good potential for further development of this methodology, when the weighting feature of the program is used to equalize the importance of the variables.

The present research is not, of course, the last word on the development of this methodology, and it shows both strengths and weaknesses. One of its strengths is that it made use of survey/salvage data that might otherwise have been superficially described and buried away in a cabinet forever. Another of its strengths is that the laboratory methods used are extremely 
quick, easy, and cheap, requiring only a caliper and a simple chemical balance.

The major weakness of the present research is the lack of firm temporal controls on the sample. My reliance on surface and undated excavated materials precluded any firm conclusions about the time of the bow's introduction into the area. Typological dating provides only a rough time scale for my sample.

I believe that further development of this methodology would be useful and worthwhile. The measuring process could be speeded by the elimination of length from the measurements. A more sophisticated electrictype balance would also serve to speed the laboratory work. Doubtless the computer work could have been handled more quickly and easily by someone with previous computer experience. I had virtually none.

The ultimate test of this methodology would involve its use on a welldated, well-stratified site or series of sites. This could be done using a method whereby the researcher making the measurements is unaware of the stratigraphic and geographical provenience of the points in the sample. Two sites whose collections of points would serve as a test of this methodology would be Hogup Cave, Utah, and Roaring Springs Cave, Oregon, because of their deep stratigraphic columns and radiocarbon chronologies. I would be especial$1 y$ interested in using the latter because of its close proximity to the Malheur area. If the break between the two K-means clusters could be strongly related to the cultural sequences of several stratified sites, I would consider that the methodology could be applied to a new surface sample to provide both temporal and functional information about the new sample. 


\section{REFERENCES}

Aiken's, C. Melvin, et al

1970 Hogup Cave. University of Utah Anthropological Papers, No. 93.

Baker, W. E. and A. V. Kidder

1937 A Spear-Thrower from Oklahoma. American Antiquity, 3:1:51.

Binford, L. and M. Papworth

1962 The Eastport Site. Anthropological Papers, Museum of of Anthropology, University of Michigan, No. 19.

Browne, Jim

1938 Antiquity of the Bow. American Antiquity, 3:4:358-359.

Corliss, David W.

1972 Neck Width of Projectile Points: An Index of Cultural

Continuity and Change. Occasional Papers of the Idaho State

Museum, No. 29.

Cressman, L. S. and A. D. Krieger

1940 Early Man in Oregon: Archeological Studies in the Northern Great Basin. University of Oregon Monographs, Studies in Anthropology, No. 3:16-52

Cressman, L. S.

1977 Prehistory of the Far West. University of Utah Press, Salt Lake City.

Dalley, G. F.

1970 "Artifacts of Wood" in Hogup Cave, Aikens et a1. University of Utah Anthropological Papers, No. 93:153-186.

Fagan, John L.

1973 Altitherma1 Occupation of Spring Sites in the Northern Great Basin. University of Oregon Doctoral Dissertation, University Microfilms, Ann Arbor.

Fenenga, Frank1in

1953 The Weights of Chipped Stone Points: A Clue to their Functions. Southwestern Journa1 of Anthropology, 9:309-323.

Forbis, R. G.

1960 The 0ld Woman's Buffalo Jump, Alberta, National Museum of

Canada Bulletin, No. 180. Contributions to Anthropology.

Gould, Richard

1969 Yiwara: Foragers of the Western Desert. Scribners, New York. 
Heizer, R. F.

1951 Preliminary Report on the Leonard Rockshelter Site,

Pershing County, Nevada. American Antiquity, 17:2:89-98.

Hester, T. R.

1973 Chronological Ordering in Great Basin Prehistory. Contributions, University of California Archeological Research Facility, No. 17 .

$\mathrm{Hi11}, \mathrm{M}$. W.

1948 The Atlat1 or Throwing Stick: A Recent Study. Tennessee Archeologist, $4: 4: 37-44$.

Jennings, J. D.

1974 Prehistory of North America. McGraw-Hill, New York.

Kidder, A. V.

1938 Arrow Heads or Dart Points? American Antiquity, 4:1:156-157

Krause; $F$.

1902 Schleudervorrichtungen fur Wurwaffen. Intemationale

Archiv fur Ethnographie, 4:4:121-151.

Massey, W.C .

1961 The Survival of the Dart-Thrower on the Peninsula of

Baja California. Southwestern Journal of Anthropology,

17:81-93.

Mildener, M. P.

1974 "Descriptive and Distributional Notes on Atlatls and

Atlat1 Weights in the Great Basin", in Great Bas in Atlat 1

Studies (Heizer, ed.). Ballena Publications in Archeology,

Ethnology, and History, No. 2 .

O1sen, L. D.

1967 Outdoor Survival Skills. Brigham Young University Press, Provo.

Pope, S. T.

1921 Yahi Archery. California University Publications in American

Archeology and Ethnology, 13:3:103-131.

1923 A Study of Bows and Arrows. California University Publications in American Archeology and Ethnology, 13:9:329-414.

Spencer, L.

1974 "Replicative Experiments in the Manufacture and Use of a Great Basin Atlatl", in Great Basin Atlatl Studies (Heizer, ed.). Ballena Publications in Archeology, Ethnology, and History, No. 2 .

Wheat, M.

1968 Survival Arts of the Primitive Paiute. University of 
Nevada Press, Reno.

Wyckoff, D. G.

1964 The Cultural Sequence at the Packard Site. University of Oklahoma Research Institute, Archeological Site Reports, No. 2 . 